Portland State University

PDXScholar

4-12-1985

\title{
A Comparison of Pedophiles and Incest Offenders on MMPI Scales and Demographic Data
}

Linda Darmer Ladd

Portland State University

Follow this and additional works at: https://pdxscholar.library.pdx.edu/open_access_etds

Part of the Psychology Commons

Let us know how access to this document benefits you.

\section{Recommended Citation}

Ladd, Linda Darmer, "A Comparison of Pedophiles and Incest Offenders on MMPI Scales and Demographic Data" (1985). Dissertations and Theses. Paper 3429.

https://doi.org/10.15760/etd.5308

This Thesis is brought to you for free and open access. It has been accepted for inclusion in Dissertations and Theses by an authorized administrator of PDXScholar. Please contact us if we can make this document more accessible: pdxscholar@pdx.edu. 
AN ABSTRACT OF THE THESIS OF Linda Darmer Ladd for the Master of Science in Psychology presented April 12, 1985.

Title: A Comparison of Pedophiles and Incest Offenders on MMPI Scales and Demographic Data.

APPROVED BY THE MEMBERS OF THE THESIS COMMITTEE:

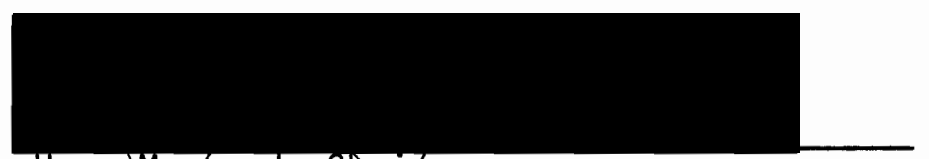

Hugo Mayhard, Chairman
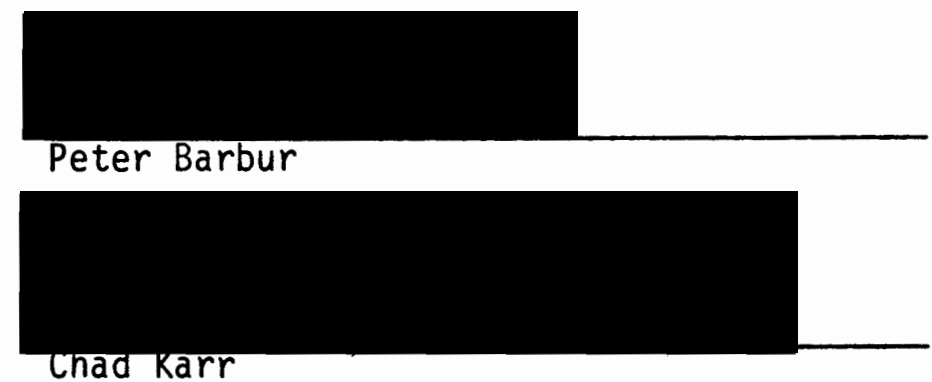

This study compared one group of pedophiles, two groups of incestuous fathers, and two groups of incestuous stepfathers on their individual MMPI scale scores and self-reported demographic data. Past research on sex offenders has shown that patterns of variables are better indicators of offender typology than single variables. A nonrandom sample of male abusers $(\underline{N}=177)$ was drawn from two separate sources, a clinic that screens offenders for treatment disposition and an unrelated outpatient treatment clinic in the Portland, Oregon area. Scores from the 13 MMPI scales as well as data from 17 demographic 
variables were drawn from clinic interviews and intake records of the offenders. The demographic data included age of the offender, educational level, age at first marriage, number of marriages, number of juvenile and adult arrests, number of jobs, number of past inpatient treatment periods, outpatient treatment periods, and incarcerations, alcohol consumption level, recreational drug usage, adoption status, and incidence of foster care, physical, and sexual abuse. Of these variables, several are susceptible to error in self-report, especially alcohol consumption leve1, which may be subject to the usefulness of a particular report to the offender. Hence, one statistical analys is was made eliminating alcohol consumption level as a variable.

Five analyses were run using the SPSS discriminant analysis program. From these, the first two analyses yielded two statistically significant functions. Analysis 2 did not include alcohol consumption level as a variable, while Analysis 1 did. When the discriminant coefficient scores of the five offender groups were plotted for both Analyses 1 and 2, the five subject groups divided into three clusters. As one cluster, the scores for the pedophiles separated clearly and distinctly from the other four offender groups. As a second cluster, one father group separated from the remaining three groups, al though not as distinctly as the pedophile cluster. The scores of the remaining father group and two stepfather groups fell close to the group mean. The separation of the two father groups is difficult to explain since fathers and stepfathers could be expected to have more similarities than not. 
The final step of this discriminant analysis program was the predicted classification of offenders according to their discriminant function scores. The predicted membership of all five groups into their respective groups fell significantly above chance. The overall adequacy of classification in both Analyses 1 and 2 fell above 49.7\%. While statistically this is an acceptable classification rate, it is inadequate for use in the assessment or treatment situation.

Continued research into offender variable patterns is suggested in order to yield a valuable assessment tool. Several variables, such as adoption status, foster care, number of incarcerations, number of arrests, and alcohol consumption level, proved informative. Tighter operational definitions for qualitative self-report data such as alcohol consumption level are necessary to improve accuracy. It is possible that the differences between the two father groups lay in the different assessment procedures used by the screening and outpatient clinics. At the outpatient clinic, patients are rigorously screened to maximize treatment potential. On the other hand, the screening clinic accepts all offenders, as its function is to suggest the future treatment disposition of the offender to the court. Future research should continue to examine patterns of variables as discriminants between offender types. Additional variables to those included in this study may provide more information on fathers and stepfathers. 
A COMPARISON OF PEDOPHILES AND INCEST OFFENDERS

ON MMPI SCALES AND DEMOGRAPHIC DATA

by

LINDA DARMER LADD

A thesis submitted in partial fulfillment of the requirements for the degree of

MASTER OF SCIENCE

in

PSYCHOLOGY

Portland State University

1985 
TO THE OFFICE OF GRADUATE STUDIES AND RESEARCH:

The members of the Committee approve the thesis of Linda Darmer Ladd presented April 12, 1985.

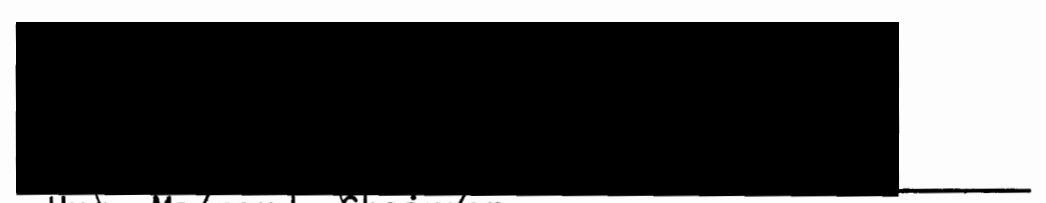

Huge Maynard, Qhairman
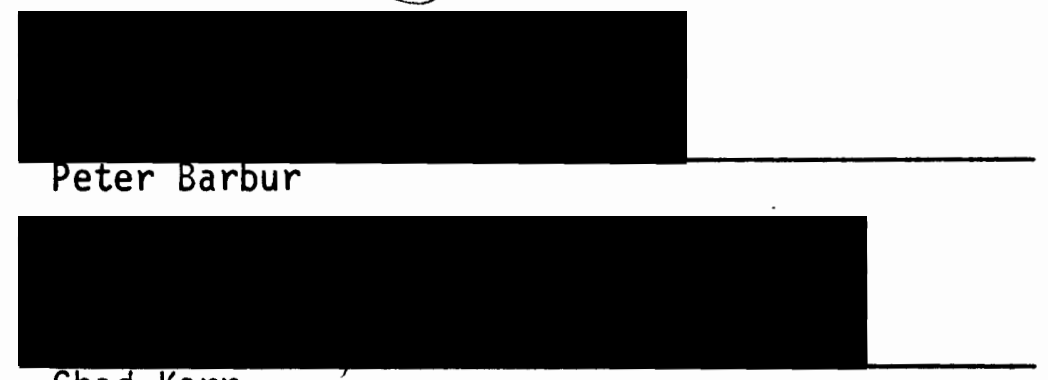

Chad Karr

APPROVED:

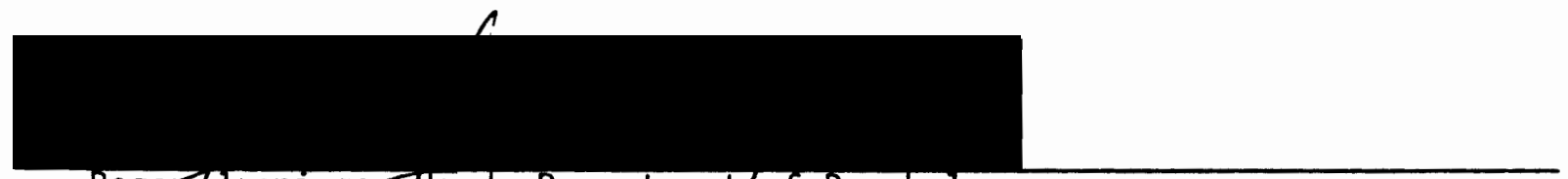

Roger/Jennings, flead, Department/ of Psychology

Jim F. Heath, Dean of Graduate Studies and Research 


\section{ACKNOWLEDGMENTS}

I am indebted to Dr. Kevin McGovern and Mr. Peter Barbur for their generosity in contributing the data for this thesis. I am particularly grateful to Dr. Hugo Maynard for his willingness to accept yet another project into his busy schedule. Thank you to Dr. Chad Karr and Mr. Peter Barbur for serving on my committee and reading so many drafts of my study. The support and hard work of Jean Crisp helped me through the darkest hour of the thesis. Finally, the advice and concern of the late Dr. Walter Klopfer were of enormous guidance. 
TABLE OF CONTENTS

PAGE

ACKNOWLEDGMENTS

LIST OF TABLES ....................

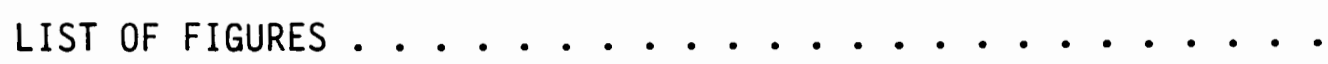

CHAPTER

I INTRODUCTION .......................... 1

MMPI Research on Sex Offenders........ 2

Demographic Research on Sex Offenders . . . 6

II METHOD ................

Subjects .............

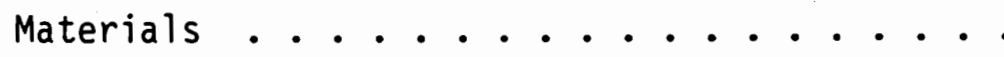

Procedure .............. 13

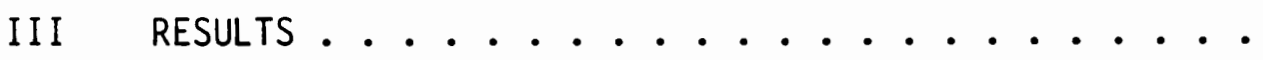

Discriminant Analyses ..........

Discriminant Functions ..........

Discriminant Analysis Classification .....

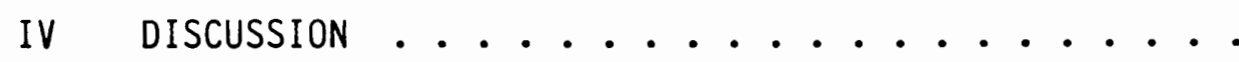

Comparison of Analyses 1 and 2......

Naming the Discriminant Functions .....

Classification Reliability........ 
PAGE

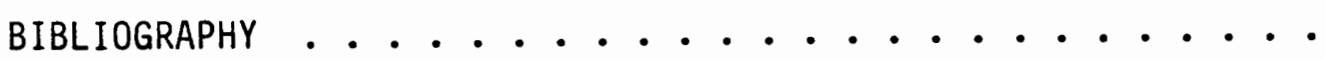

APPENDIX A: DEMOGRAPHIC QUESTIONNAIRE \& RAW DATA FREQUENCIES .

APPENDIX B: ANALYSES 1 AND 2 SIGNIFICANCE LEVELS ...... 
LIST OF TABLES

TABLE

PAGE

I Research on MMPI Scale Differences Between Sex Offender Groups . . . . . . . . .

II Studies Analyzing Age, Education, Marriage, and

Alcohol Consumption Data on Sex Offenders . .

III Frequencies and Percentages of Demographic

Variables Within Groups .........

IV MMPI Group Mean K-Corrected Scores and Standard

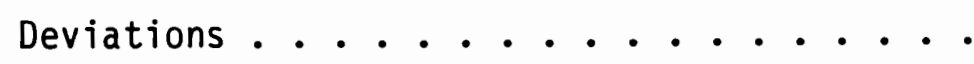

$\checkmark \quad$ Analysis 1: 12 Discriminant Variables .....

VI Analysis 2: 10 Discriminant Variables Without

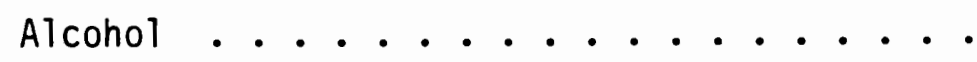

VII Analysis 5: 5 Discriminant MMPI Scales.....

VIII Discriminant Functions .............. 30

IX Analysis 1: Classification 1 With Alcohol .... 33

$X$ Analysis 2: Classification 2 Without Alcohol ...

XI Raw Data Frequencies of Demographic Variables by

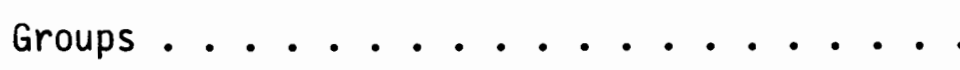

XII Analysis 1 Significance Levels: 12 Discriminant Variables ..............

XIII Analysis 2 Significance Levels: 10 Discriminant Variables ............. 


\section{LIST OF FIGURES}

FIGURE

PAGE

1. MMPI Mean Profiles for Five Offender Groups ..... . 21

2. Significant Variables Expressed as Distance Between

Pairs of Offender Groups .......... 26

3. Plots of Centroids Based on Mean Discriminant Function

Coefficient Scores for Each Group . . . . . 32 


\section{CHAPTER I}

\section{INTRODUCTION}

Child sexual abuse has been of interest to psychologists since 1896 when Freud published his hypothesis that hysteria could be attributed to sexual trauma in childhood (cited in Freud, 1896). In recent years professional groups, including psychologists, have become concerned about the extent of child sexual abuse. Various terms used to describe offenders are child rapist, child molester, incest offender, and pedophile. These terms are being used interchangeably or with great overlap in definition. Varying operational definitions of child molestation, incest, and pedophilia have often led to experimental results which are confusing to interpret. The term child molester has been used generically to include the range of child sexual abuses from rape to exposing. Early researchers adopted the following definition of incest in their work: "sexual intercourse between two persons, married or not, who are too closely related by blood or affinity to be married" (Karpman, 1957, p. 10). This operational definition of incest has expanded in light of research. In 1965, Gebhard, Gagnon, Pomeroy, and Christianson included as sexual activities the following behaviors which they found occurred more commonly between adults and children than sexual intercourse: oral-genital contact, fondling of genitals, mutual masturbation, and homosexual incest (cited in Meiselman, 1978). It has been suggested also that attempted sexual activity, such as displaying 
of genitals in a sexual context, be included as incestuous behavior (Meiselman, 1978). Sgroi (1982) defined incest broadly, encompassing any form of sexual activity between a child and a parent, stepparent, or extended family member. She stressed that a familial relationship is the crucial psychosocial dynamic in incest and stated that the "presence or absence of a blood relationship between incest participants is of far less significance than the kinship factors" (Sgroi, 1982, p. 10).

Karpman defined pedophilia as a "gratification from sexual intimacies with children which includes exposure of the genitals, manipulation of the child, or penetration, partial or complete" (Karpman, 1957, p. 15). Swanson (1968) defined the child molester in legal terms as an individual who has been charged and convicted of a crime stemming from sexual behavior with a minor. The child molester may prefer adult partners, whereas, according to Swanson, the pedophile's sexual interests are almost exclusively involved with children. Toobert, Bartelme, and Jones (1959) defined a pedophile as a person whose sexual object is any child who is 12 years or younger. Groth (1979) described the pedophile as having a cross-generational sexual preference. He has diagnosed these men as having a fixated psychosexual development which leads them to be attracted to children.

\section{MMPI RESEARCH ON SEX OFFENDERS}

Psychological researchers have endeavored to distinguish sex offenders from normal groups through the use of special scales derived from the Minnesota Multiphasic Personality Inventory (MMPI). Marsh, 
Hilliard, and Liechti (1955) attempted to develop a sexual deviation scale from the MMPI items which would distinguish individuals convicted of sexual offenses from normal individuals. In three replications, Peek and Storms (1956), Holz, Harding, and Glassman (1957), and Yamahiro and Griffith (1960) concluded that the scale constructed by Marsh et al. measured generalized psychiatric adjustment rather than sexual deviancy. Toobert et al. (1959) attempted to use the MMPI to isolate a pedophile scale $(P e)$, using the same statistical method as Marsh. Toobert's scale has been used by Panton $(1978,1979)$ to compare incest offenders, rapists, and peciophiles with incarcerated offenders in a prison setting. Panton found a significant difference between pedophiles and rapists of children on the Pe scale. To date, Panton is the only published researcher since Toobert who has tested the Pe scale.

More recently, researchers have attempted to identify sex offenders through MMPI code clusters or by comparing special groupings, such as husbands and wives. In 1978, Skinner and Jackson used an empirical clustering analysis on a group of sex offenders to test the following code types: neurotic (scales 1-2-3), psychotic (scales 8-7), and sociopathic (scales $4-7$ ). Their data did not support classifying sex offenders according to these psychopathological types. Anderson, Kunce, and Rich (1979) regrouped rapists, child molesters, and incest offenders according to three MMPI code types (scales F-8, 4-9, and 2-4) and found significant differences on demographic data between the three code types. In her study on incest, Fredrickson (1981) compared three groups of husbands and wives on their MMPI scale score differences. The groups 
were as follows: incest therapy, non-incest therapy, and a normal group.

Table I lists studies in which the MMPI has been used to differentiate between sex offender groups and between sex offender and control groups. Rada (1978) noted that as early as 1945, Schmidt administered the MMPI to a group of convicted sex offenders diagnosed as psychopathic, reporting that scales 5,6 , and 8 were elevated above $I=70$. Incestuous fathers and stepfathers have been compared with child molesters (Panton, 1979), with a control group (Kirkland \& Bauer, 1982), and in husband and wife pairs in therapy groups (Fredrickson, 1981). Pedophile studies are rarer: Pittman (1982) compared pedophiles and incestuous fathers, and Roby (1982) compared pedophiles and rapists. Most child molester studies, which group incestuous fathers and pedophiles in with other sexual deviants, have found scale 4 to be the highest elevated scale for all groups (Armentrout \& Hauer, 1978; Panton, 1978; Swenson \& Grimes, 1958). Armentrout and Hauer (1978) compared the MMPI scores of rapists of adult women, rapists of female children, and non-rapist sex offenders (which included incest and pedophiliac offenders). In an ambitious study, Langevin, Paitich, Freeman, Mann, and Handy (1978) compared five sex offender groups on both their MMPI scores and the Cattell 16PF. The groups were as follows: homosexual pedophiles, heterosexual pedophiles, incestuous fathers, exhibitionists, and multiple deviants. Mccreary (1975) compared a group of 33 convicted child molesters divided into two groups based on number of arrests. 


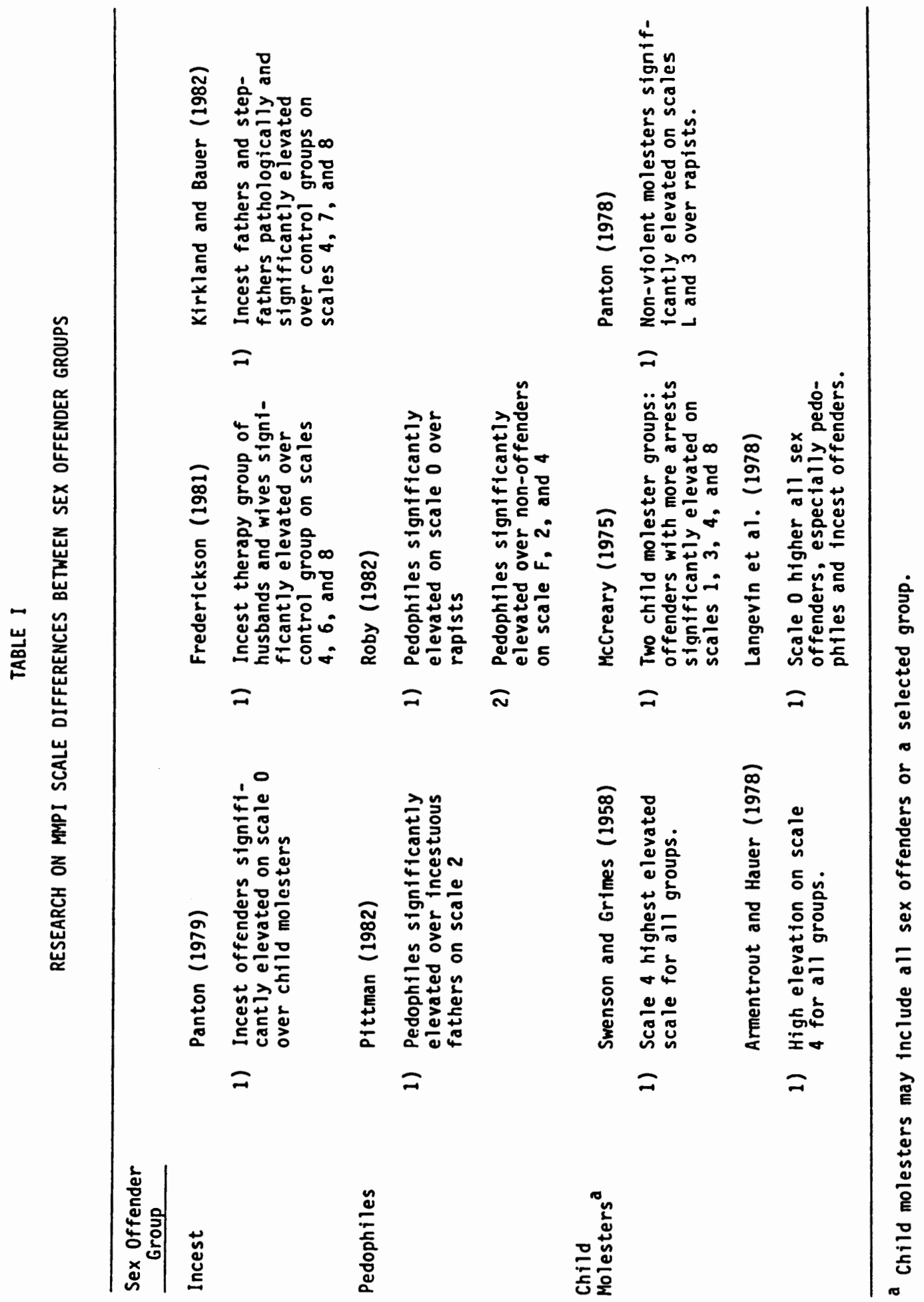




\section{DEMOGRAPHIC RESEARCH ON SEX OFFENDERS}

MMPI data have not, as yet, clearly differentiated between the sex abusers who are termed child molesters, pedophiles, and incest offenders. Some studies of sex offenders have included analyses of demographic variables, as can be seen in Table II. Groth pointed out that while rapists had an acting out range of between ages 20 and 40 , pedophiles usually began their careers younger and continued later in life than rapists. The majority of sex offender studies included in Groth's paper found the age range of sex offenders of children to be from 30 to 45 years. The highest educational level attained by most sex offenders is high school with a smaller proportion reaching college.

The home environment of the offender and later marriages have also been investigated. Fredrickson (1981) found that the incest group in her study was more conservative, had a lower socioeconomic position, were of Catholic faith, and had had more prior marriages and children than a control group. Kirkland and Bauer's (1982) group of incest offenders reported having marital problems. In Swenson and Grimes" study (1958), 18\% of the first-time prison offenders had come from broken homes, while $4 \%$ had been raised in orphanages, and $78 \%$ had been raised in intact families. In the sample studied by Toobert et al. (1959), 42\% of the pedophiliac offenders had lived in intact homes until the age of 15 , while $58 \%$ came from broken homes.

The relationship between alcohol and the commission of sexual crimes has been of keen interest to investigators. Meiselman (1978) reported that most studies which included alcohol found that 20 to $50 \%$ 


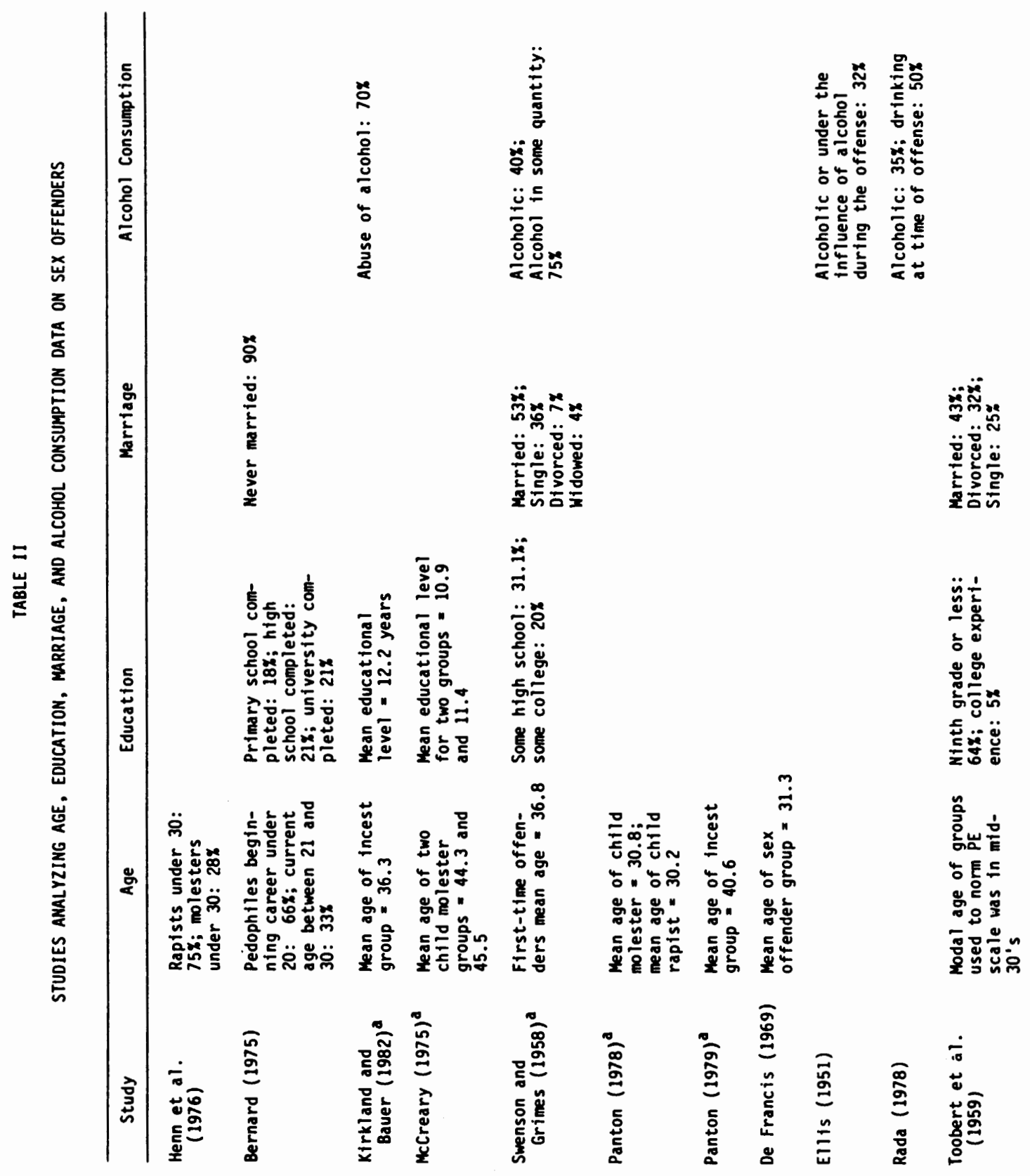


of their samples drank heavily. Renvoize (1982) stated that researchers generally agreed that over $32 \%$ of incest offenders drank excessively. Finkelhor (1979) stated that almost all researchers have found a high degree of alcoholism (ranging from 30 to $50 \%$ ) among incest offenders. Groth (1979) reported that in his prison population, alcohol was an important factor in the offense committed by the regressed pedophile, more commonly termed the incest offender. According to Groth, the fixated pedophile has little or no history of alcohol abuse, as he is more child-like psychologically than the regressed offender. Henn, Herjanic, and Vanderpearl (1976) reported that alcohol and drug abuse played an important role in the incest offenses of their sample.

Prior sexual victimization of offenders has been studied by rearchers. Pelto (1981) compared the childhood sexual experiences of incest offenders and non-offenders with a self-report questionnaire. Although the difference was not statistically significant, offenders had experienced more varieties of sexual abuse from both male and female perpetrators and had witnessed more incestuous behavior than the nonoffender group. Kirkland and Bauer (1982) found that only one of thirty offenders in their sample reported a past history of incest in his own childhood. Ellis (1951) reported that $45 \%$ of his sample showed severe emotional deprivation from childhood experiences. He noted that those men incarcerated for incest and non-coital sexual relations with minors had especially high incidences of emotional deprivation.

Kinship relations between offender and victim have only begun to be studied. Both Sgroi (1982) and Finkelhor (1979) noted the loosening of 
family structure as the number of stepfamilies has increased. To date, most fathers and stepfathers are combined into single offender groups (Kirkland \& Bauer, 1982). De Francis (1969) noted that 14\% of the incestuous group in his offender sample were fathers, while $13 \%$ were stepfathers, a disproportionate figure when general population norms were considered. Meiselman (1978) stated that girls growing up with stepfathers had a higher risk of being sexually abused. Finkelhor (1979) noted that $29 \%$ of the father offenders in his study were stepfathers, while $71 \%$ were fathers. He considered this a high percentage of stepfathers, since only $5 \%$ of the total sample reported having a stepfather.

In summary, the definitions of both pedophile and incest offender nave broadened in light of research concerning the sexual experiences occurring between adults and children. Analyses of MMPI scale differences between pedophiles and other offender groups revealed that the following scales tended to be statistically significantly elevated for the pedophiles: $F, 2,4$, and 0 . Likewise the following scales tended to be statistically significantly elevated for the incest offender: $2,4,6,7,8$, and 0 . Demographic variables appear to have correlational significance, especially age, consumption of alcohol, and past history of sexual abuse experienced by the offender. To date, research has only begun to point to possible differentiating factors between these two child sexual offender groups. The purpose of this study will be to compare pedophiles, incestuous fathers, and incestuous stepfathers by using a discriminant analysis program to reveal profiles 
which emerge from their individual MMPI scale scores and demographic data. The following variables are included in this study:

Demographic Variables

MMPI Scales

Age of offender

Highest education level

Age at first marriage

Number of marriages

Number of juvenile arrests

Number of adult arrests

Number of past incarcerations

Number of jobs

Military service: yes/no

Number of treatments as psychiatric inpatient

Number of periods of outpatient treatments

$L$

Alcohol consumption level

Recreational drug usage: yes/no

$\mathrm{F}$

Adopted: yes/no

Foster care: yes/no

Physically abused as child: yes/no

Sexually abused as child: yes/no 


\title{
CHAPTER II
}

\author{
METHOD
}

\section{SUBJECTS}

The first offender group consisted of males who were being evaluated by a clinical psychologist practicing in Portland, Oregon. These subjects $(\underline{N}=93)$ were referred to the psychologist on a nonselected basis after being arrested for child sexual abuse and mandated for sexual evaluation by the courts or at the request of their lawyers. The first group of subjects comprised three subgroups: incestuous fathers $(\underline{n}=36)$, incestuous stepfathers $(\underline{n}=26)$, and pedophiles $(\underline{n}=$ 31), whose mean ages were $39.7,41.8$, and 39.9 , respectively. These subjects 7 ived throughout Oregon and in Clark County, Washington. For the purposes of this study, the subgroups were labeled as follows: fathers(1), stepfathers(1), and pedophiles(1).

A second offender group $(\underline{N}=84)$ was obtained through the Providence Day Treatment Program in Portland, Oregon. This program accepts sex offenders on the basis of their amenability to the treatment program offered at the clinic, excluding voyeurs, exposers, and men who are brain-damaged, psychotic, violent, or who lack a sense of remorse. The men were referred to this program by the courts or by Children's Services Division (CSD). The two subgroups in this study were labeled incestuous fathers(2) and incestuous stepfathers(2), with sample sizes 
of 36 and 48 , respectively. The mean age of fathers(2) was 38.4 and of stepfathers(2) was 37.9 years. This group of offenders entered therapy from all areas in Oregon.

\section{MATERIALS}

Each subject from both groups had completed a short form of the Minnesota Multiphasic Personality Inventory (MMPI), a self-report, truefalse questionnaire comprised of 399 items which took approximately two hours to complete. The test contained four validity scales and ten clinical scales, of which scale $Q$ was omitted from this study. The validity scales provided information as to the subject's approach to test taking, such as faking good or bad, lying, and defensiveness. The ten clinical scales can be combined into patterns reflecting the absence or presence of psychological disorders. Raw scores were obtained for each scale of the test based on the number of items marked in the scored direction. Raw scores were K-corrected and converted into standardized I scores for each scale (Kaplan \& Saccuzzo, 1982).

The Demographic Questionnaire, comprised of 17 variables, was devised by the contributing clinical psychologist. The variables for this questionnaire were obtained from the clinical interview the psychologist included as a part of each offender's clinical evaluation. The data should be considered self-report. A copy of the Demographic Questionnaire is included in Appendix $A$ and provides further definition of the variables. 


\section{PROCEDURE}

A11 subjects were given the MMPI short form. The contributing psychologist had the Demographic Questionnaires from his group of subjects coded and made the data available to this author. Demographic data on the subjects from the Providence Day Treatment Program were coded by this author according to the variables listed in the Questionnaire. Both demographic data and MMPI scale scores from all subjects were then entered into a discriminant analysis program.

Both groups signed consent to release information forms when they entered evaluation privately and at the Day Treatment Program. The subsequent treatments of these subjects was in accordance with the ethical standards of the APA. While these men were not a random sample of sex offenders, they did constitute a random sample of those sex offenders referred for psychological evaluation in the Oregon-Vancouver, Washington area. 


\section{CHAPTER III}

\section{RESULTS}

Initially, descriptive statistics were obtained on all demographic variables for all five groups of sex offenders: fathers(1), stepfathers(1), pedophiles(1), fathers(2), and stepfathers(2). For a description of each group, refer back to the Method section: Subjects. The frequencies and percentages for each demographic variable are shown by group in Table III. The raw data have been broken down by group and placed in Appendix A. Data on the following variables were collected for analysis:

Age of offender

Highest education level

Military service

Number of marriages

Age at first marriage

Number of jobs

Number of treatments as a psychiatric inpatient

Number of periods of outpatient treatment

Number of juvenile arrests

Number of adult arrests

Number of past incarcerations

Alcohol consumption level

Recreational drug usage

Foster care
Adopted

Physically abused as child

Sexually abused as child

MMPI scales

$\mathrm{L}$
$\mathrm{F}$
$\mathrm{K}$
1
2
3
4
5
6
7
8
9
0

In obtaining additional statistics, cells with zero frequencies were collapsed within the following variables: Jobs (10 or more), Psychiatric Inpatient Treatments ( 1 or more), Outpatient Treatment 


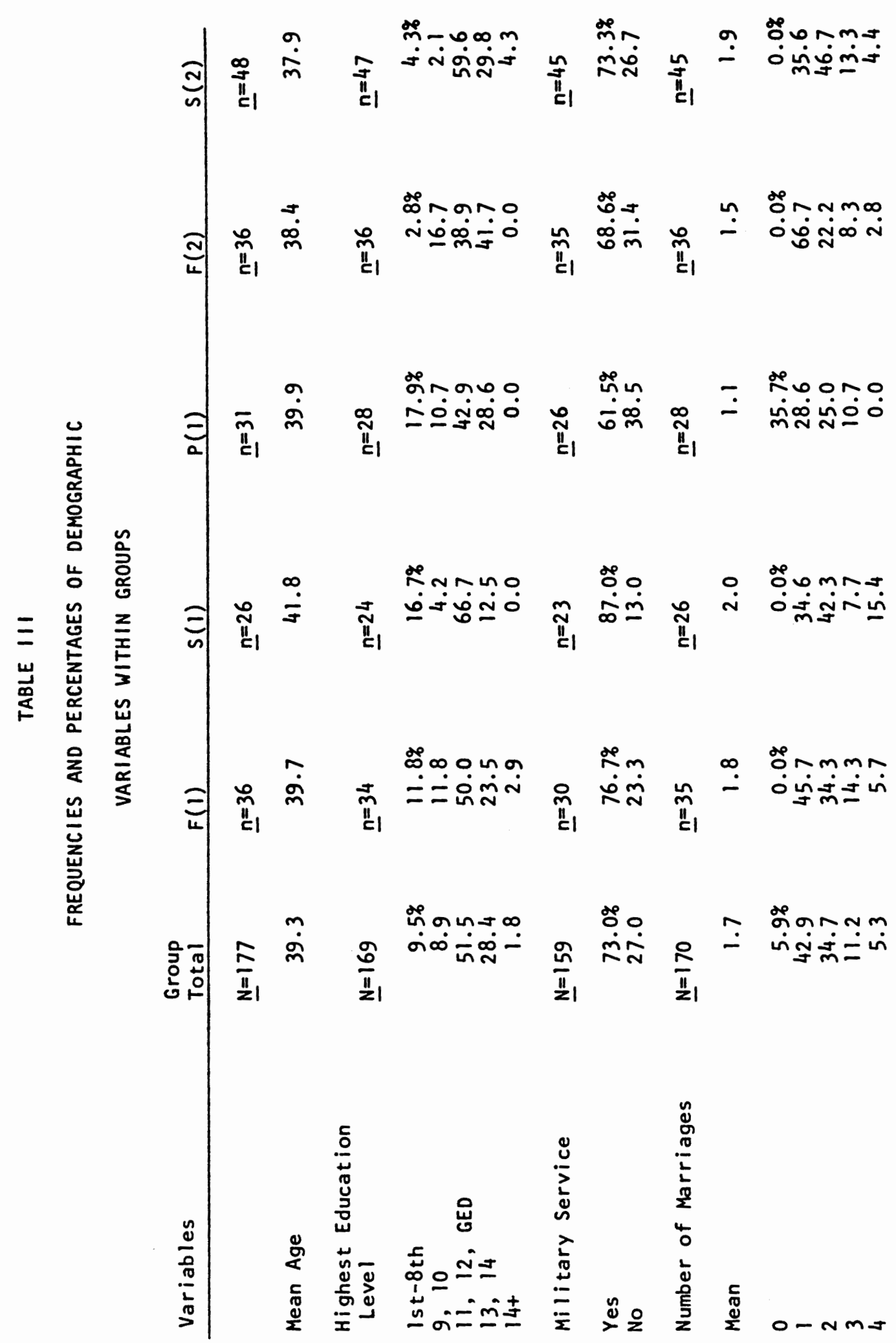




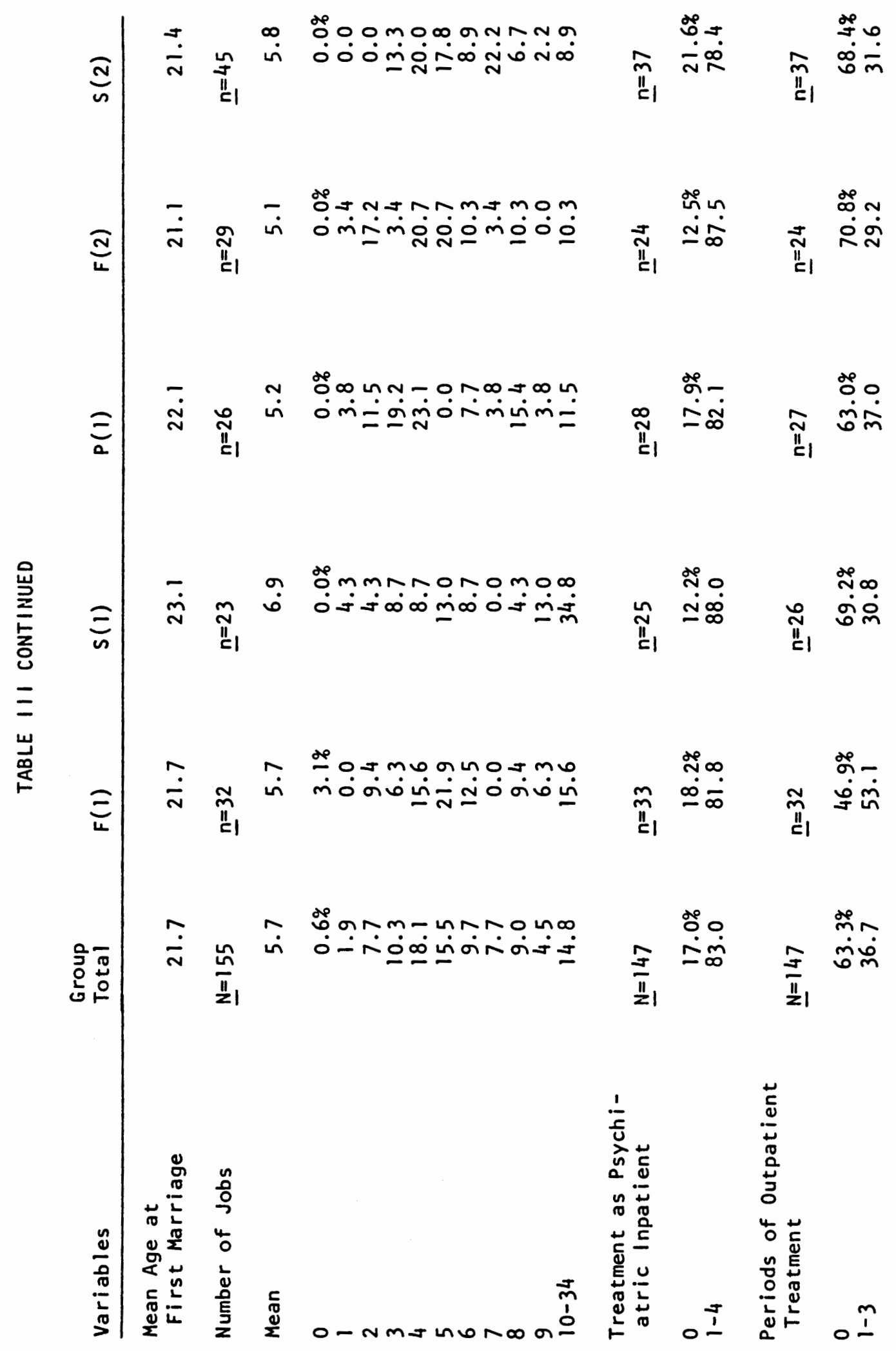




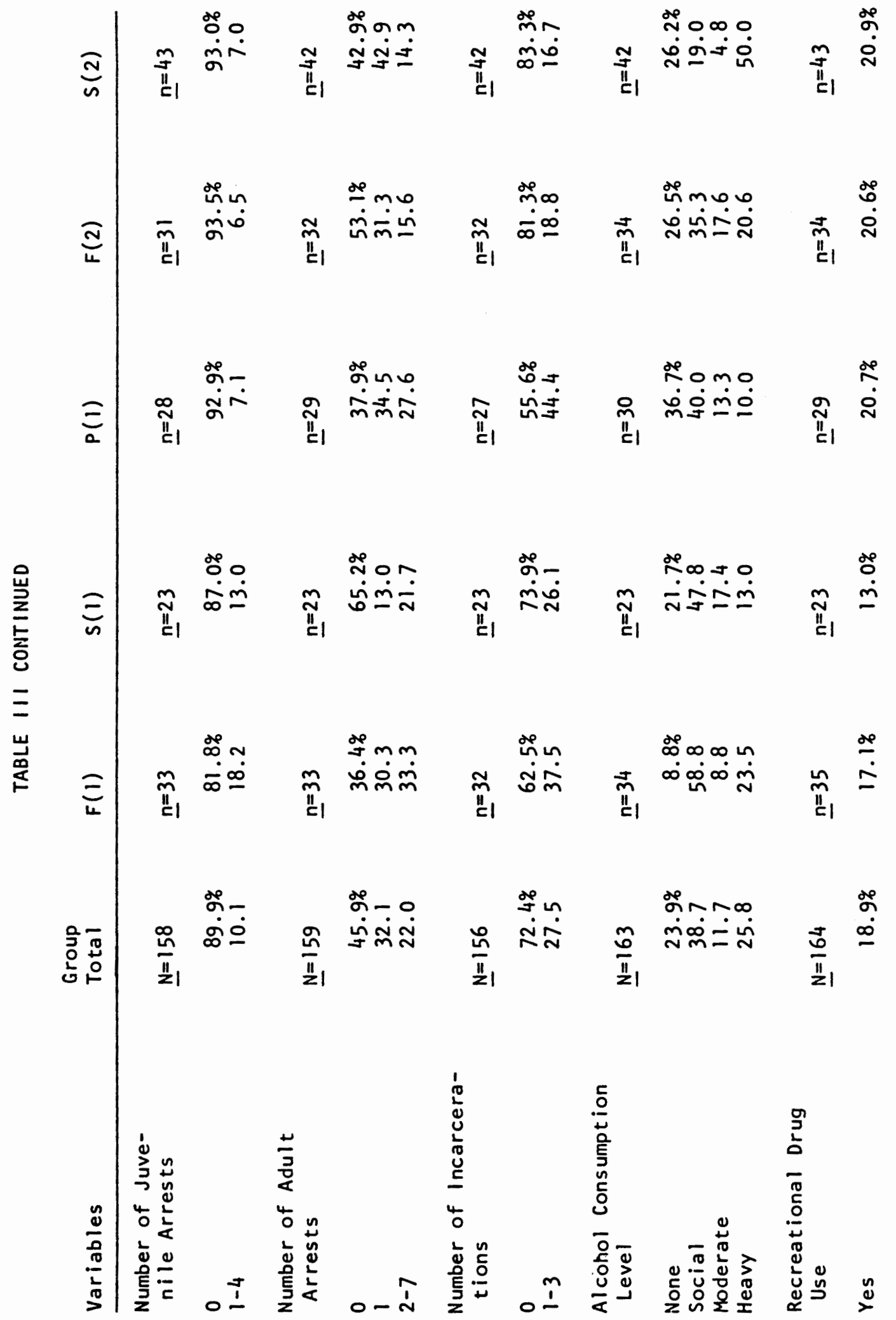




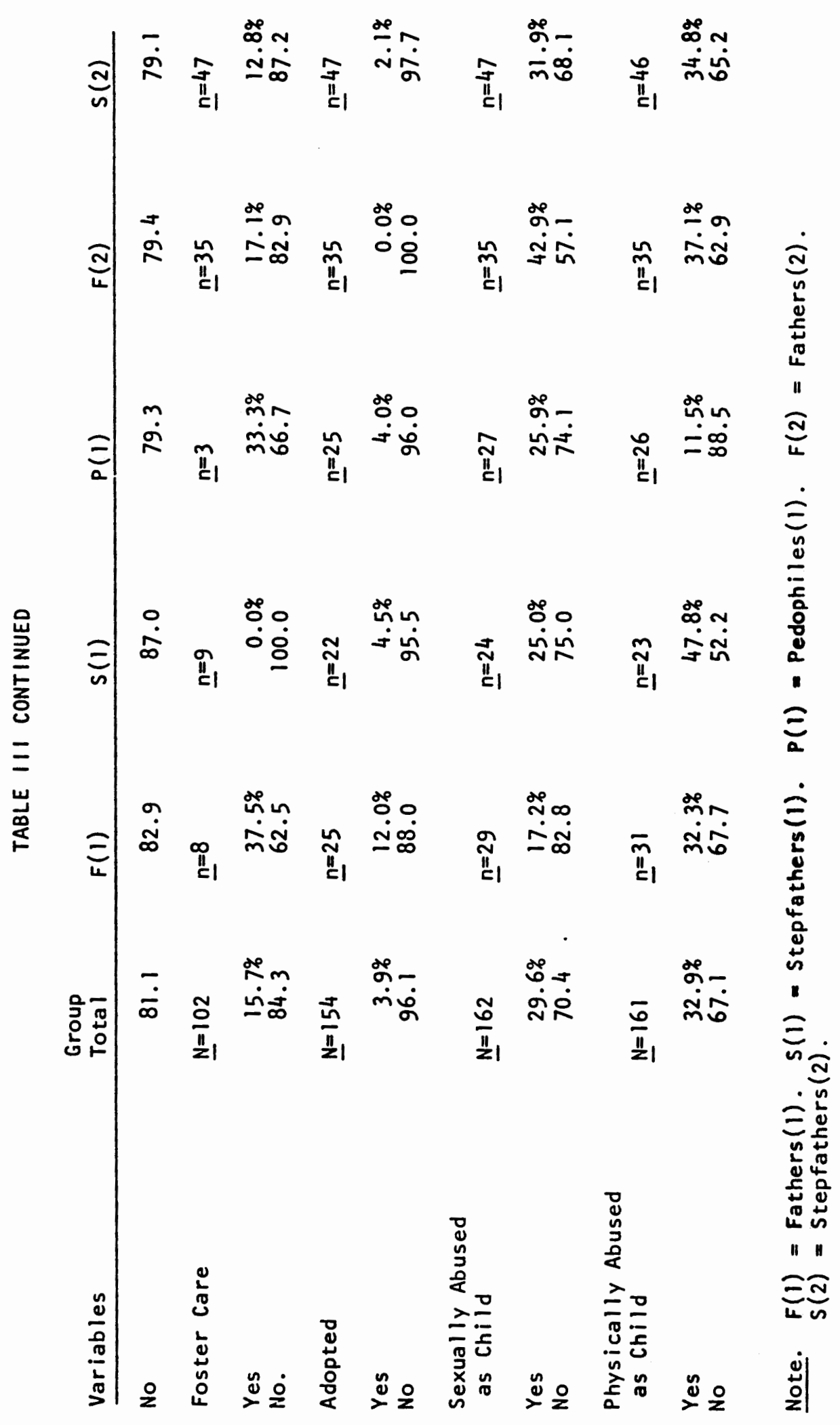


Periods (1 or more), Juvenile Arrests (1 or more), Adult Arrests (2 or more), and Number of Incarcerations ( 1 or more). For a more complete definition of these variables, see Appendix A.

Descriptive statistics were also run on the MMPI scale scores for each subject. The mean group $K$-corrected scores and standard deviations are listed in Table IV, while the group profiles are plotted in Figure 1.

\section{DISCRIMINANT ANALYSES}

A stepwise discriminant analysis program was used in order to select the "best" set from 30 possible variables, which would produce the greatest separation between the five groups. This stepwise analys is was run on the data using as the selected method Rao's V, a generalized distance measure. The computer-selected variables were chosen according to the largest amount of $V$, centralized distance, each added when joined with previous variables. At the beginning of each step, each selected variable was tested to determine whether the amount of centroid separation it added to the previous variables was significant in terms of $\underline{F}$ ratio. If one variable contributed the same information previously contributed by another variable, the variable contributing less of this same information would be dropped. The end result is the optimal set of variables with non-redundant information which best separated the groups. Due to missing data for some subjects across the demographic variables, the computer could analyze all 177 subjects on only the MMPI scales. It was decided to keep the sample size as large as possible on 


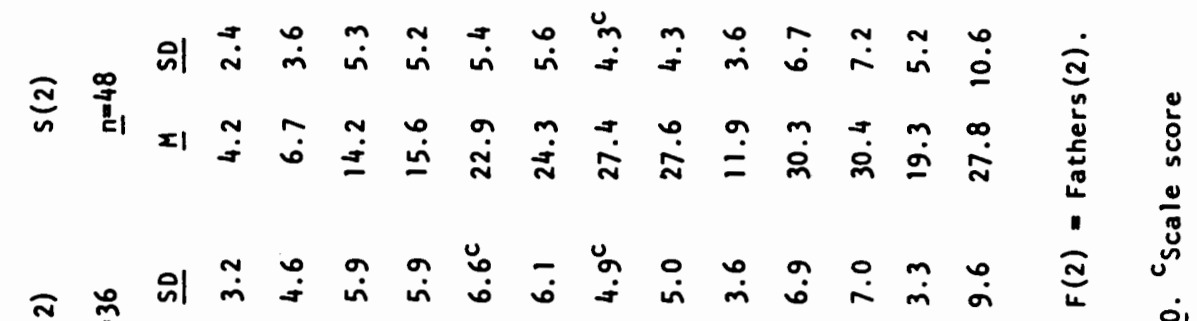

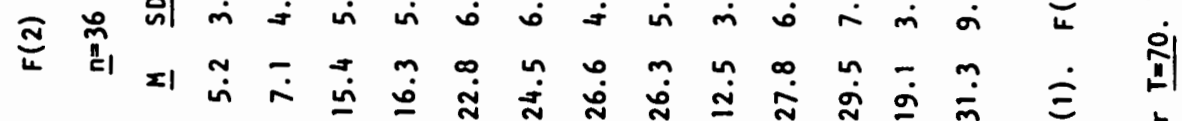

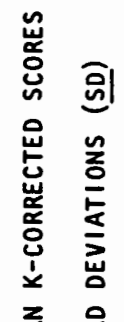

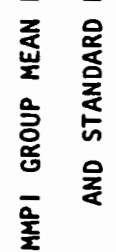

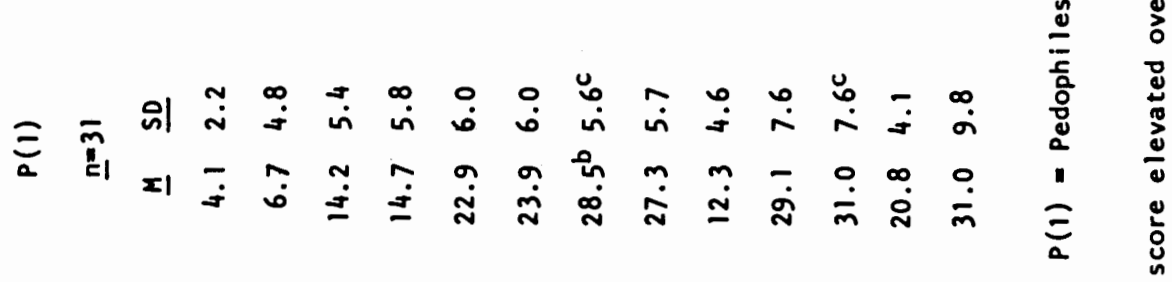

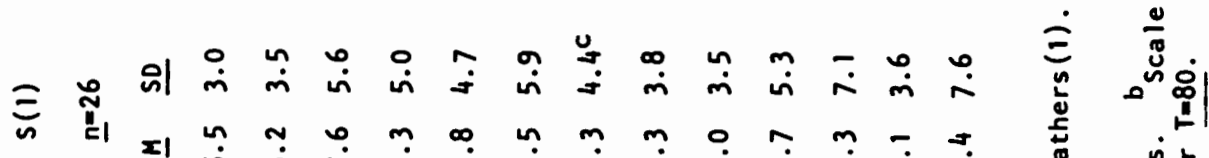

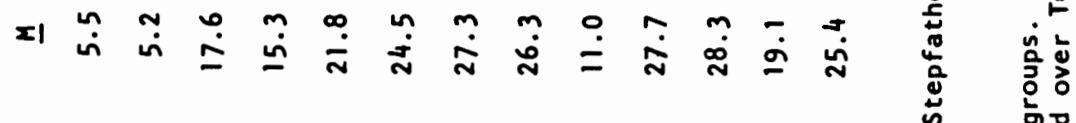

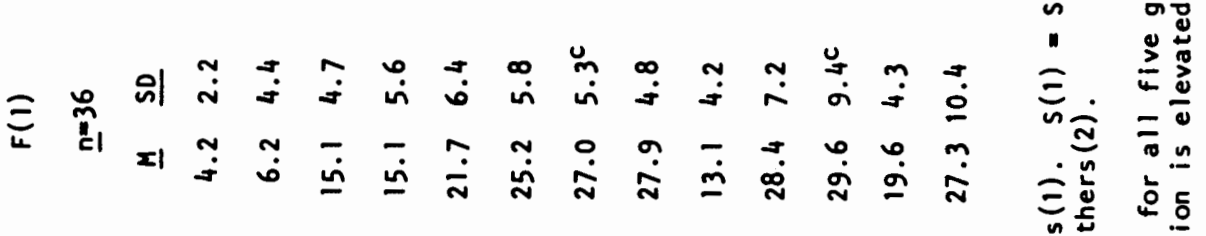

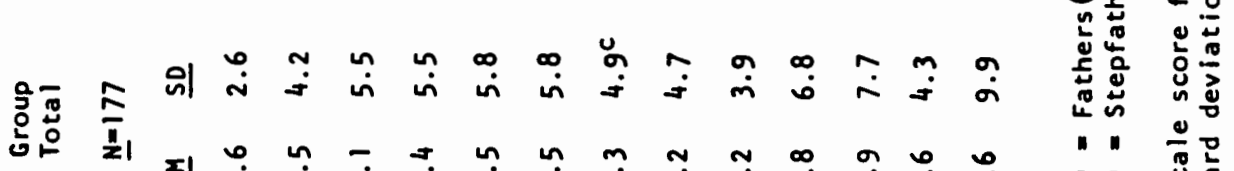

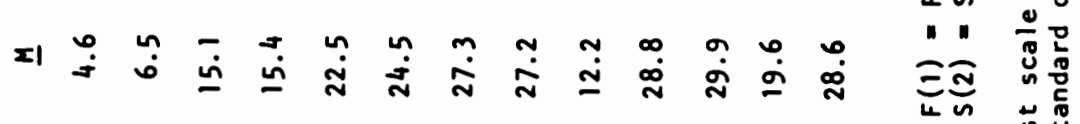

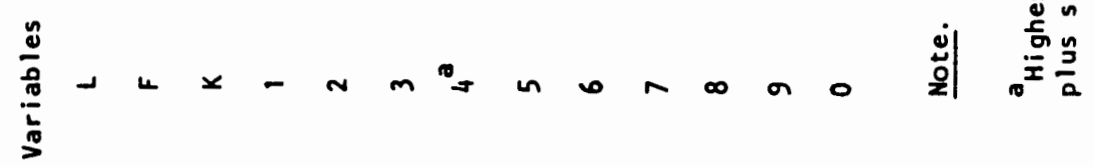



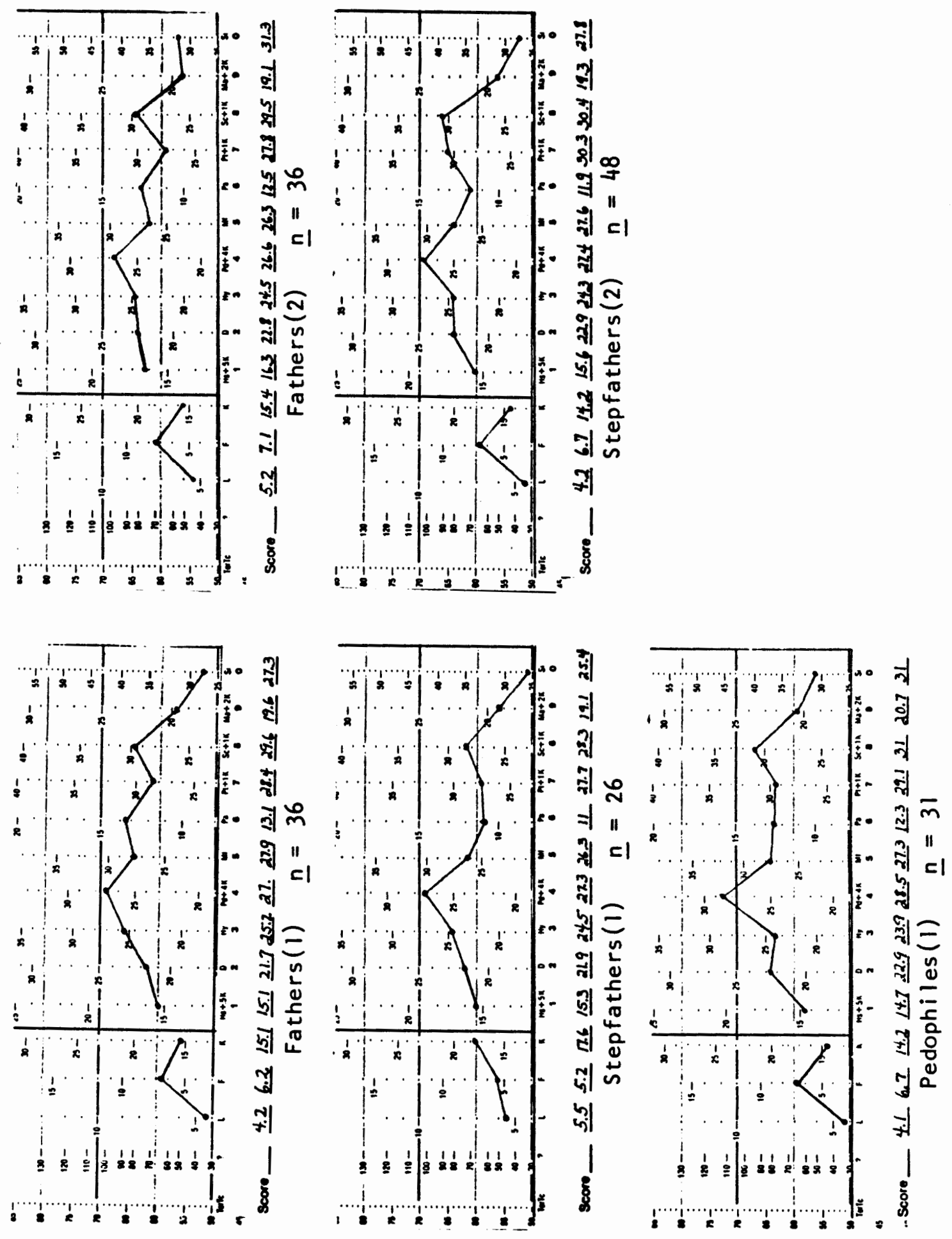

Figure 1. MMPI mean profiles for five offender groups. 
Analysis 1 and eliminate variables which were missing the most information. Consequently, the five groups $(\underline{N}=144)$ in Analysis 1 were compared on 20 of the 30 variables. Twelve of these 20 variables proved to be discriminant and are listed below in order of their descending Rao value:
Number of marriages
MMPI scale 0
Alcohol consumption level
Physically abused as child
Highest education level
MMPI scale 9

\author{
MMPI scale 7 \\ MMPI scale 6 \\ MMPI scale 1 \\ MMPI scale $K$ \\ MMPI scale 4 \\ Sexually abused as child
}

The variables which were eliminated are as follows: Age of offender, Recreational Drug Usage, and MMPI scales L, F, 2, 3,5, and 8. Table V summarizes the interaction between the groups as a result of Analysis 1 . For a more detailed breakdown of interaction which includes significance levels, see Appendix B.

On Analysis 2, Alcohol Consumption Level was omitted as a variable, leaving 19 variables to be entered on 146 subjects. Ten of these 19 variables proved discriminant; in descending order of significance, they are as follows:

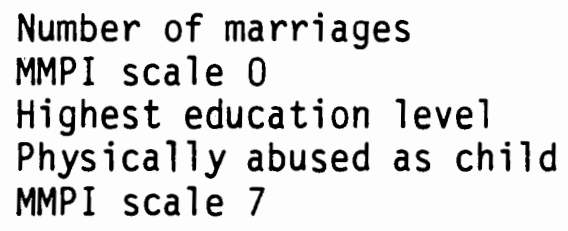
MMPI scale 6
MMPI scale 1
MMPI scale 9
MMPI scale $K$
Age of offender

The following variables were eliminated: Recreational Drug Usage, Sexually Abused as Child, MMPI scales L, F, 2, 3, 4, 5, and 8. Table VI summarizes the interaction between the variables by groups, indicating 

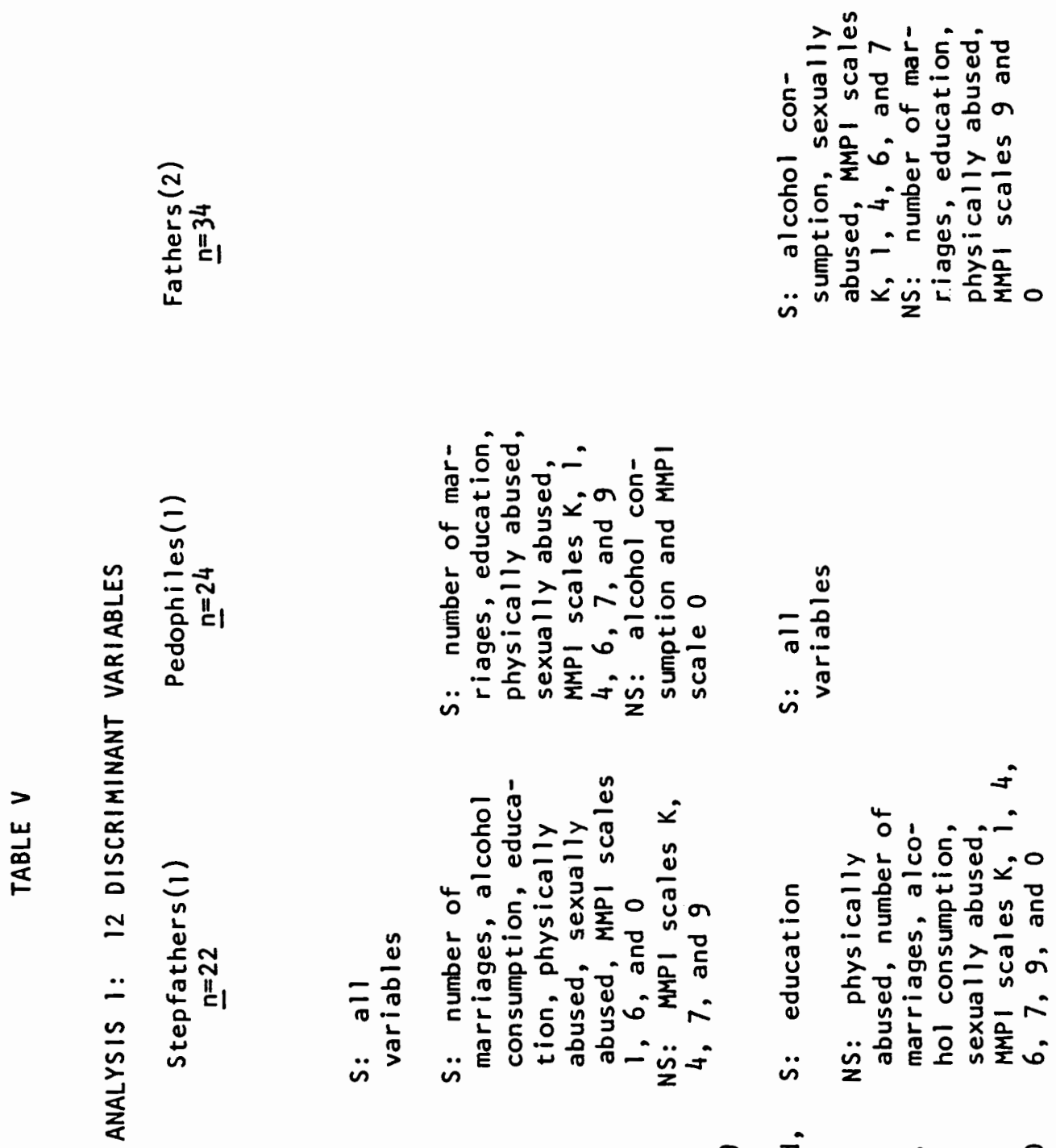

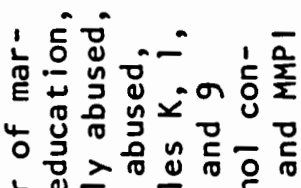

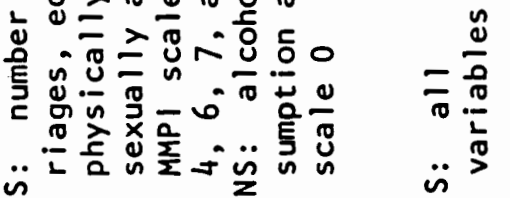

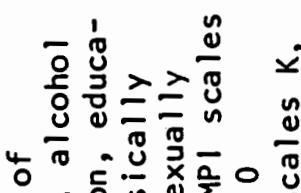

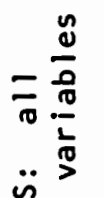

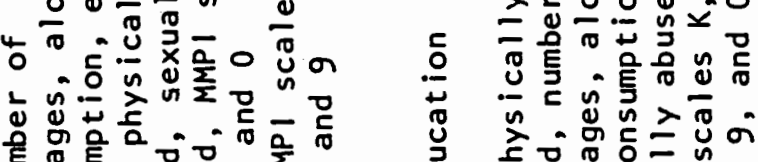
n. 药

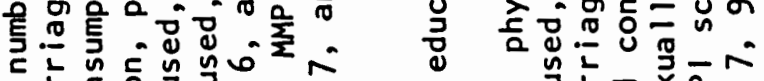

-

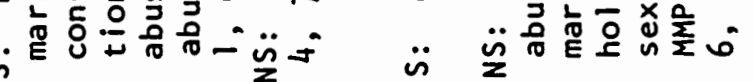

옹

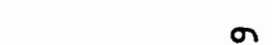

离- $\quad$ 岂

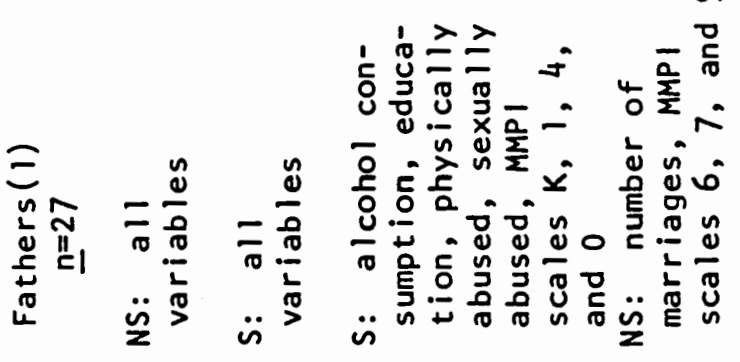

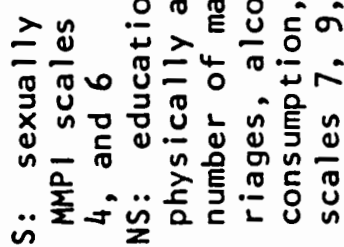

in

인

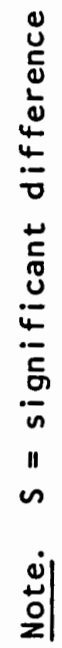

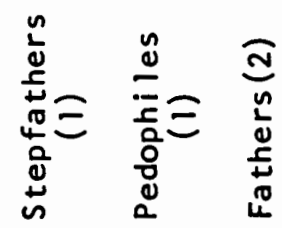

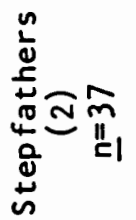



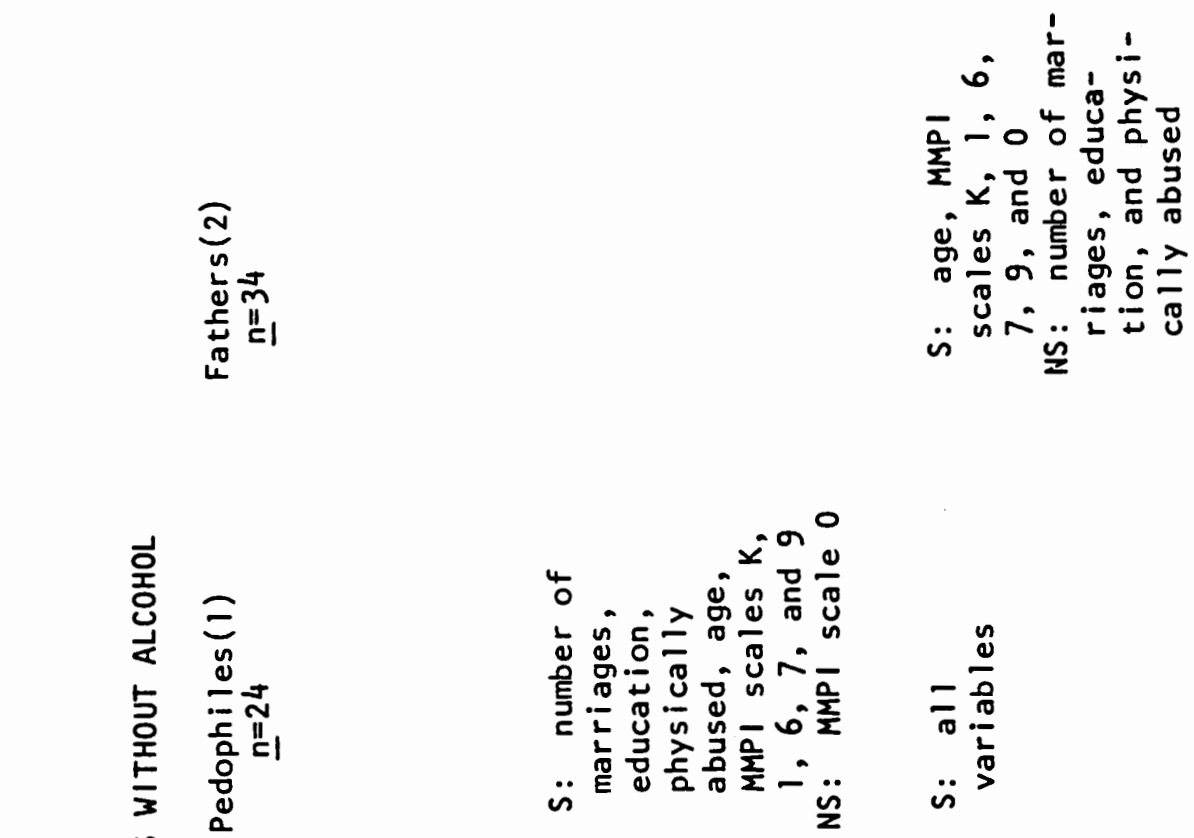

䒘

$=\frac{\frac{y}{0}}{\frac{0}{2}}=\frac{\frac{n}{0}}{\frac{\pi}{2}}$

$=\frac{\frac{0}{\pi}}{\frac{\pi}{\pi}}$

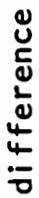

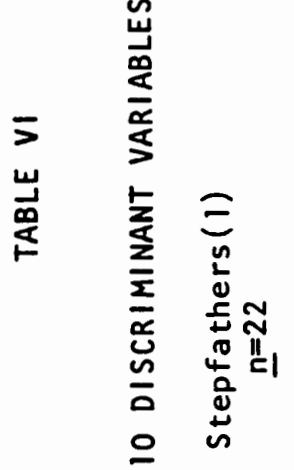

is $\ddot{n}$

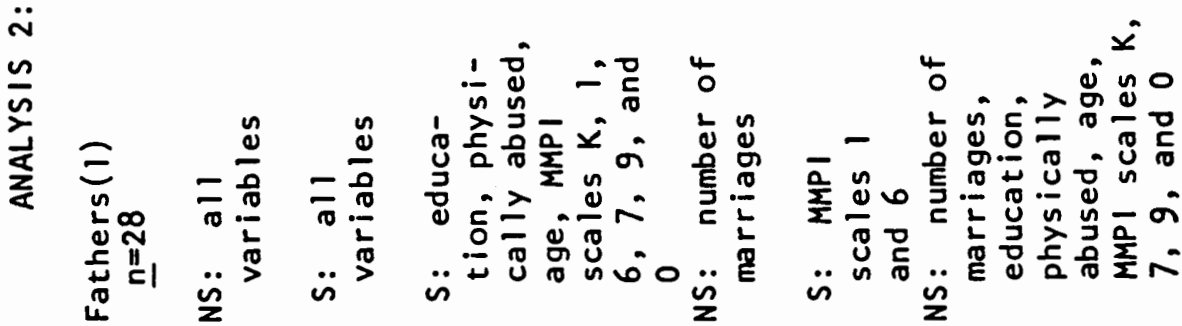

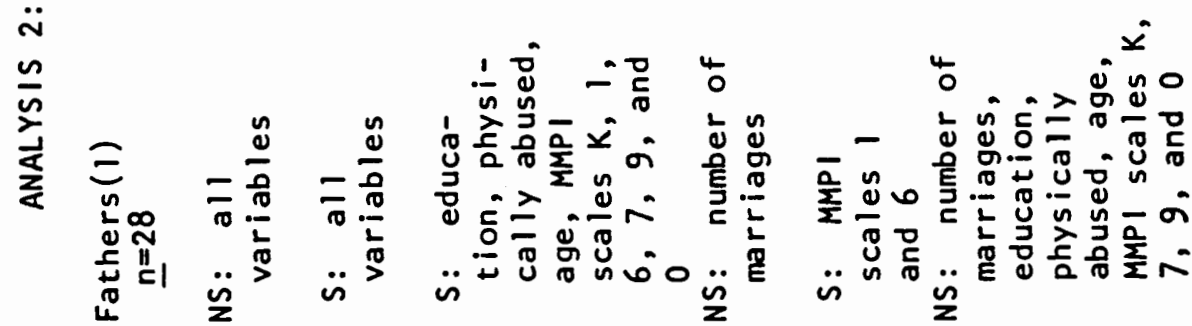

$\ddot{n}$

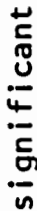


significant and nonsignificant variables in each interaction. A more detailed table providing significance levels is included in Appendix B.

Inspection of Tables $V$ and $V I$ indicates the effect achieved with and without Alcohol Consumption Level as a variable. Pedophiles(1) differed significantly from all other groups with the exception of fathers(2) on Alcohol Consumption Level and Scale 0 on the MMPI. The fathers(1) group was clearly similar on all variables analyzed with the stepfathers(1) group, making the two groups indistinguishable. Fathers(1) was more similar to stepfathers(2) than to fathers(2). Stepfathers(1) was more like stepfathers(2) on Analysis 2 than on Analysis 1. With Alcohol Consumption Level in the analysis, stepfathers(1) was more different from fathers(2). Stepfathers(2) remained an equal distance from fathers(2) on both analyses. Figure 2 presents a pictorial representation of the differences between the groups on both Analysis 1 and 2. This figure does not show the "true" distances but shows, schematically, the relative distances according to how inany variables were discriminants between each pair of groups.

For Analysis 3, all 30 variables were entered on all five groups. Due to missing data, the sample size of this analysis was reduced to $\underline{N}=$ 58. The following fourteen variables had a sufficiently large value of F to be selected as discriminant:

Highest education level Adopted

Number of jobs

MMPI scale 1

Foster care

Number of incarcerations

MMPI scale 0
MMPI scale 6

MMPI scale 8

MMPI scale 4

Number of marriages

Number of adult arrests

Sexually abused as child

Physically abused as child 

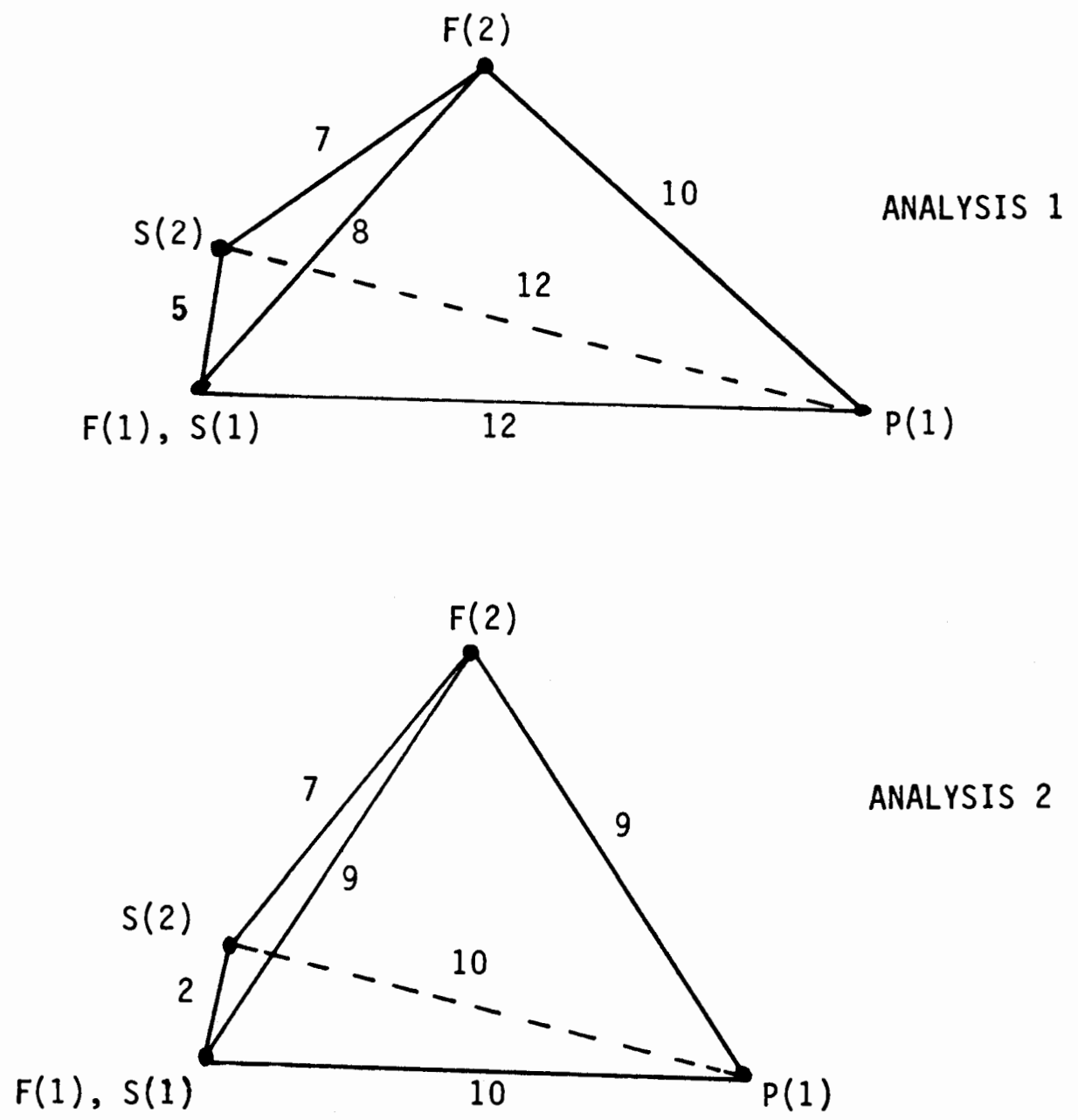

Figure 2. Significant variables expressed as distance between pairs of offender groups. These distances are schematic and do not represent the space in which the discriminants were actually computed.

Note: Arabic numerals represent the number of significant interactions. $F(1)=$ Fathers $(1), S(1)=$ Stepfathers $(1) ; P(1)=$ Pedophiles(1). $F(2)=$ Fathers(2). $S(2)=$ Stepfathers (2). 
Two variables, Recreational Drug Usage and MMPI scale F, were entered and later removed from analysis. The number of subjects in fathers(1), stepfathers(1), and pedophiles(1) dropped below seven each after missing data were eliminated in Analysis 3, while fathers(2) and stepfathers(2) maintained 21 and 26 subjects, respectively. Examination of the interaction between the first three groups was therefore meaningless. The analysis comparing fathers(2) and stepfathers(2) revealed no significant difference on any of the fourteen variables. No table has been included in this analysis.

On Analysis 4, the five groups were compared on 22 variables consisting of the 12 discriminant variables from Analysis 1 and the 10 variables originally omitted from that same analysis. A total of 58 subjects could be analyzed on these variables with the same group distribution as in Analysis 3 . The following 14 variables proved to be discriminant and are listed in descending order of significance:

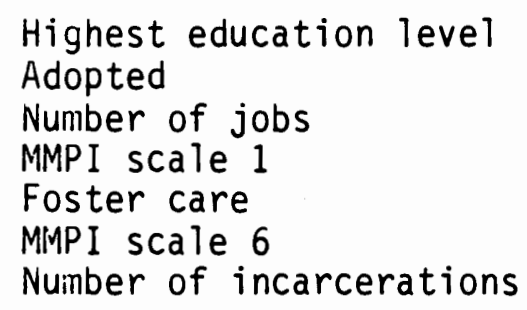

MMPI scale 0 Number of marriages Number of adult arrests MMPI scale 4 Sexually abused as child Physically abused as child MMPI scale 9

One variable, Number of Outpatient Treatment Periods, was entered and removed from analysis. As in Analys is 3, subjects from fathers(1), stepfathers(1), and pedophiles(1) were too small to allow analys is to be meaningful. A comparison of fathers(2) and stepfathers(2) revealed no significant differences between any variables. No table has been 
included for Analysis 4.

A final Analysis 5 was made comparing the entire sample by groups on their individual MMPI scale scores. Table VII displays the interaction among the following discriminant variables: $L, 4,6,7$, and 0 . Unlike Analyses 1 and 2, pedophiles(1) did not separate as a distinct group when MMPI scales alone were analyzed. No differences were revealed between pedophiles(1) and fathers(1), fathers(2), and stepfathers(2). Pedophiles(1) and stepfathers(1) did differ. Fathers(1), stepfathers(1), and stepfathers(2) showed no differences on MMPI scales. Fathers(1), stepfathers(1), and stepfathers(2) differed from fathers(2) on all MMPI scales.

\section{DISCRIMINANT FUNCTIONS}

As the final step in discriminant analysis, standardized canonical discriminant function coefficients were derived from the variables found to be discriminant. Each coefficient reflects the weighted contribution of a variable to its function; the positive and negative signs indicate direction only. The four functions which proved to be significant from Analyses 1 and 2 were included in Table VIII. No functions reached significance from Analysis 5 . Each set of functions showed sufficient discriminating power to separate the five groups along two dimensions in each analysis. The first function separated the groups linearly; the second separated them in a right-angle direction from the initial function. It is important to remember that positions of the groups, measured on all the original variables, cannot truly be represented in 

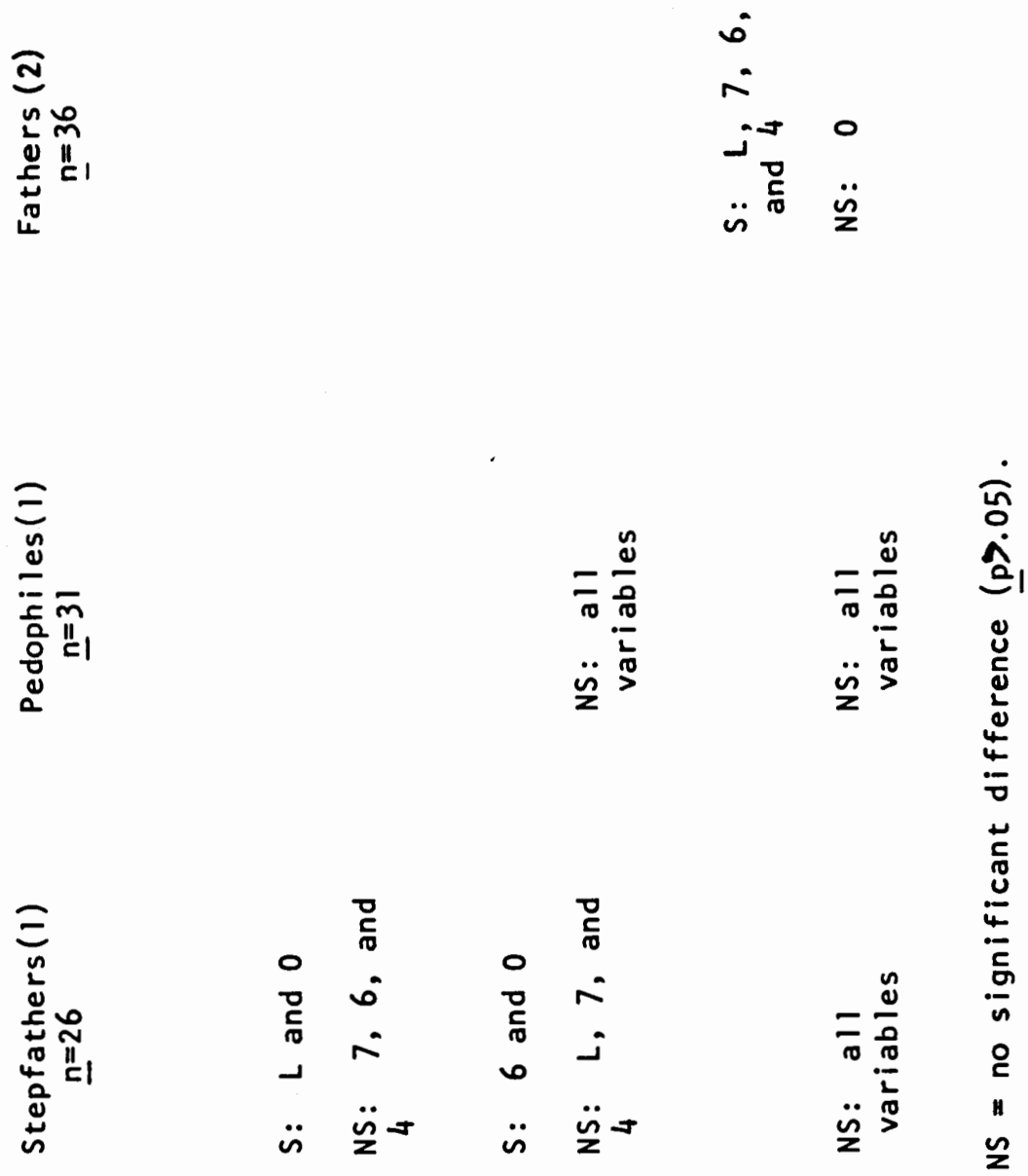

$\frac{i n}{n}$
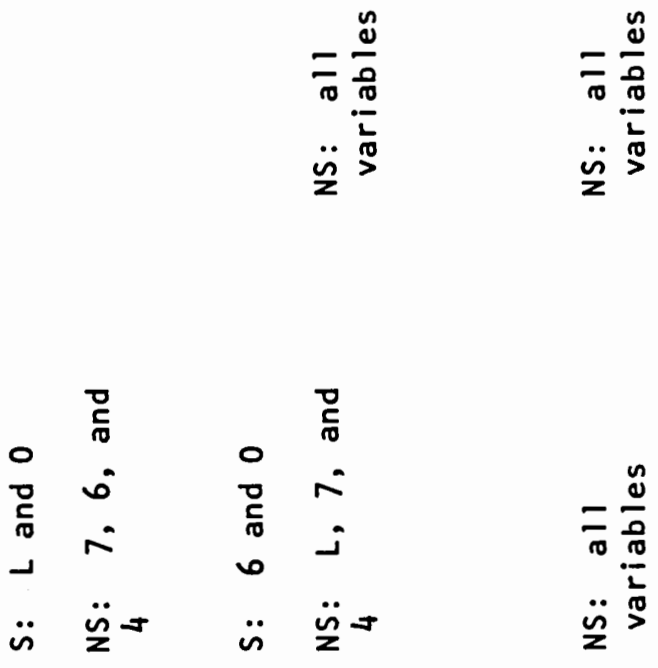

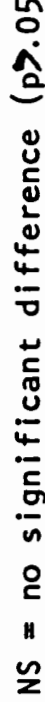

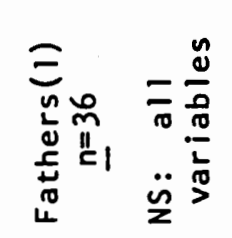

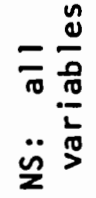

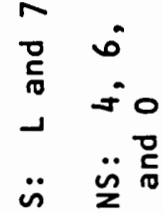

$=\frac{\frac{9}{0}}{\frac{0}{0}}$

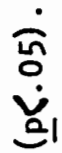

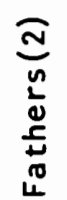


TABLE VIII

DISCRIMINANT FUNCTIONS 1

Analysis 1

Function $1(p<.0044)$

$\begin{array}{lr}\text { Number of marriages } & 0.56147 \\ \text { Physical abuse } & -0.49090 \\ \text { MMPI scale } 9 \text { (Ma) } & -0.46421 \\ \text { Alcohol consumption } & 0.45256 \\ \text { Education a } & 0.43624 \\ \text { MMPI scale 0 (Si) } & -0.35636 \\ \text { Sexually abused } & 0.22563 \\ \text { MMPI scale K } & -0.18920 \\ \text { MMPI scale 4 (Pd) } & -0.18841 \\ \text { MMPI scale 1 ( } \mathrm{Hs}) & 0.15608 \\ \text { MMPI scale 7 (Pt) } & 0.09691 \\ \text { MMPI scale 6(Pa) } & -0.04222\end{array}$

Function $2(p<.0366)$

$\begin{array}{lr}\text { MMPI scale } 7 \text { (Pt) } & -0.98246 \\ \text { MMPI scale p ( } \mathrm{Si}) & 0.84070 \\ \text { MMPI scale } 1 \text { ( } \mathrm{Hs} \text { )a } & 0.52926 \\ \text { MMPI scale 6 (Pa) } & 0.44237 \\ \text { Sexually abused } & -0.38230 \\ \text { MMPI scale 4 (Pd) } & -0.32725 \\ \text { Education } & 0.32518 \\ \text { Alcohol consumption } & 0.27457 \\ \text { Physically abused } & -0.22320 \\ \text { MMPI scale K } & 0.16763 \\ \text { Number of marriages } & -0.12143 \\ \text { MMPI scale 9 (Ma) } & 0.00643\end{array}$

${ }^{1}$ See text, page 32 for explanation. ${ }^{a}$ Cut-off point for naming function.

$\begin{array}{lr}\text { Number of marriages } & -0.12143 \\ \text { MMPI scale } 9 \text { (Ma) } & 0.00643\end{array}$
Analysis 2

Function $1(p<.0024)$

Number of marriages $\quad-0.73669$

MMPI scale 0 ( $\mathrm{Si} \quad 0.60422$

MMPI scale $9(\mathrm{Ma})^{\mathrm{a}} \quad 0.59167$

Education $\quad-0.33528$

Physical abuse $\quad 0.32599$

MMPI scale $K \quad 0.32662$

MMPI scale 1 (Hs) $\quad-0.17871$

Age $\quad 0.16435$

MMPI scale 7 (Pt) $\quad-0.10711$

MMPI scale $6(\mathrm{~Pa}) \quad 0.02138$

Function $2(p<.0024)$

MMPI scale 0 ( $\mathrm{Si} \quad 0.87583$

MMPI scale 1 (Hs) $\quad 0.76544$

Age $^{\text {a }} \quad-0.44507$

Education $\quad 0.36058$

MMPI scale $6(\mathrm{~Pa}) \quad 0.35514$

Physical abuse $\quad-0.24465$

MMPI scale K $\quad 0.18978$

MMPI scale 7 (Pt) $\quad-0.17374$

MMPI scale $9(\mathrm{Ma}) \quad-0.11377$

Number of marriages $\quad 0.09187$ 
two-dimensional space, as in Figure 3 , but if the original variables are collapsed into the two discriminant functions this makes a twodimensional display of the spatial relationships between the centroids of the groups.

For the purposes of this study, variables were arbitrarily considered dominant if they contained at least half the value of the largest coefficient in that function. Function 1 of Analys is 1 was dominated positively by Number of Marriages, Alcohol Consumption Level, and Highest Education Level and negatively by Physical Abuse as Child and MMPI scales 0 and 9. Function 2 was characterized by three variables: negatively by MMPI scale 7 and positively by scales 0 and 1 . Function 2 of Analysis 2 was characterized positively by MMPI scales 0 and 1 and negatively by Age of Offender.

The discriminant function coefficients were used to derive a single discriminant score for each subject. The centroid for each of the five groups has been plotted for both Analyses 1 and 2 in Figure 3 . The centroids for fathers(1), stepfathers(1), and stepfathers(2) were grouped closely in each scatterplot, while pedophiles(1) and fathers(2) were as far from each other as from the main group. The distances between centroids was smaller in Analysis 2 than in Analys is 1.

\section{DISCRIMINANT ANALYSIS CLASSIFICATION}

The discriminant functions from Analys is 1 and 2 were used to classify the individual subjects according to their highest probability of membership into that group, as shown in Tables $I X$ and $X$, respectively. 
FUNCTION 1
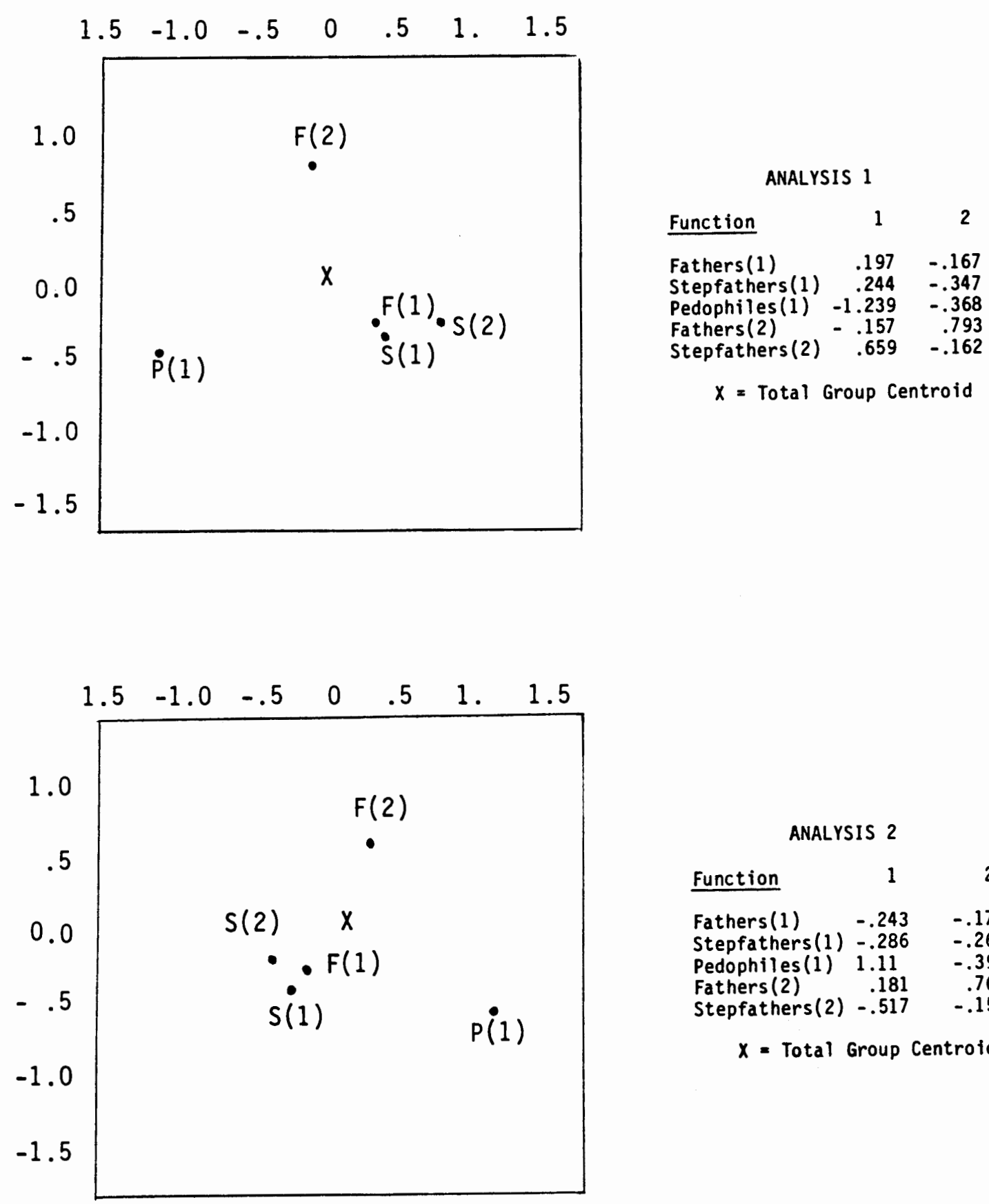

ANALYSIS 2

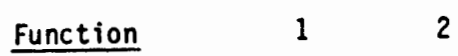

$$
\begin{array}{lcr}
\text { Fathers(1) } & -.243 & -.173 \\
\text { Stepfathers(1) } & -.286 & -.266 \\
\text { Pedophiles(1) } & 1.11 & -.394 \\
\text { Fathers(2) } & .181 & .761 \\
\text { Stepfathers(2) } & -.517 & -.151 \\
\qquad X=\text { Total Group Centroid }
\end{array}
$$

Figure 3. Plots of centroids based on mean discriminant function coefficient scores for each group. 


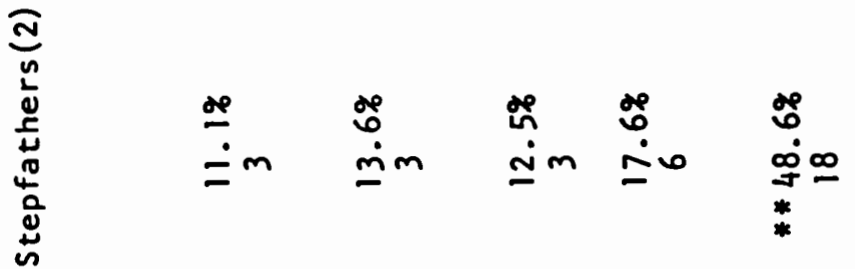

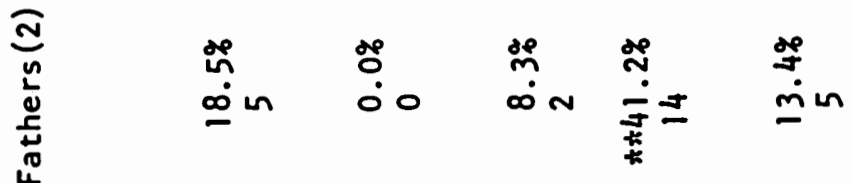

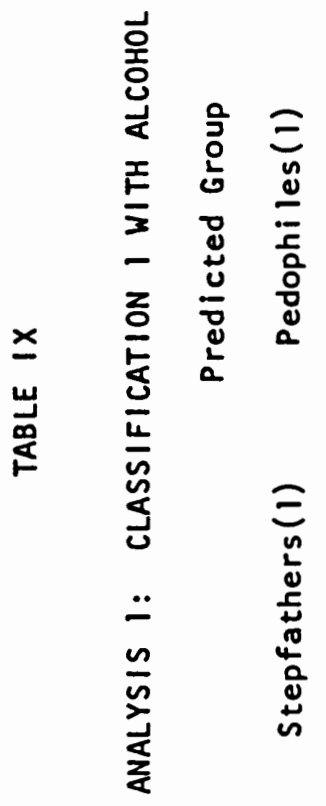

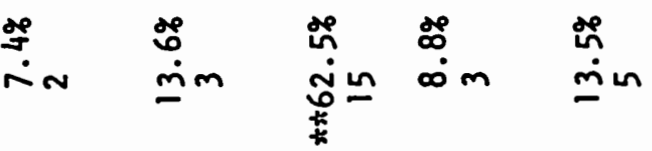

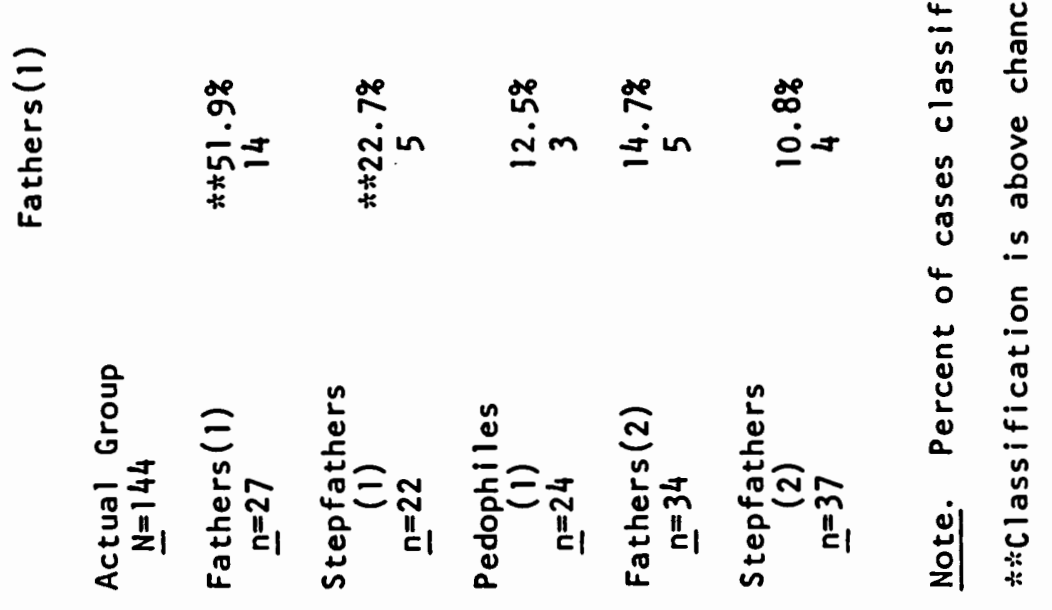




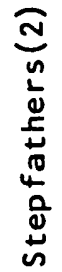

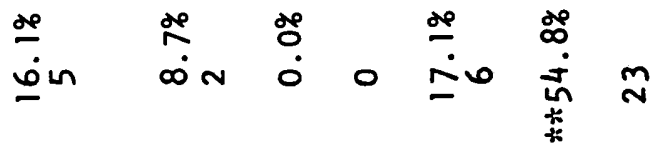

ลิ
$\frac{1}{0}$
$\frac{1}{4}$
$\frac{10}{4}$

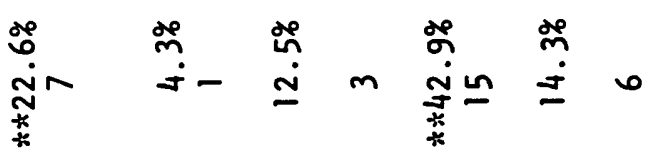

옹

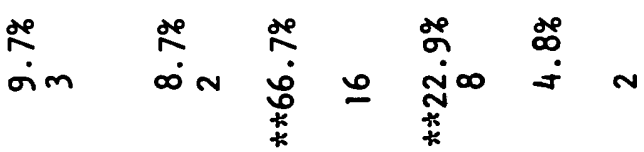

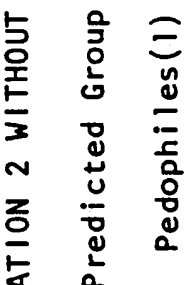

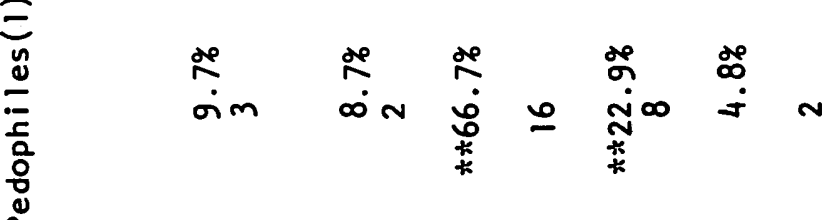

\begin{tabular}{llll}
$x$ & $z$ & $\overline{0}$ & 0 \\
\hline & $\frac{1}{E}$ & $\frac{1}{2}$ & 0
\end{tabular}

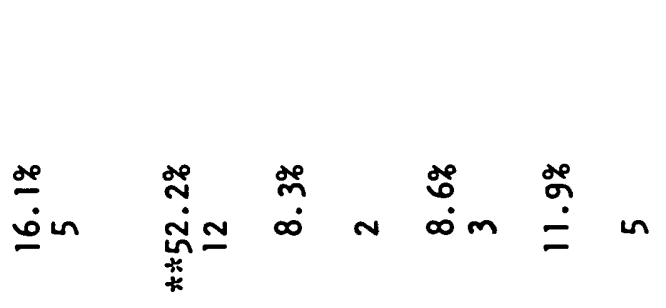

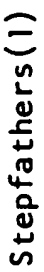

$\stackrel{n}{\frac{1}{2}} \quad$ 変

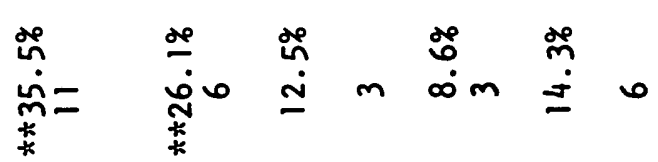

电范

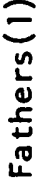

*

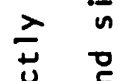

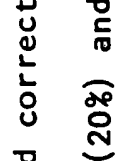

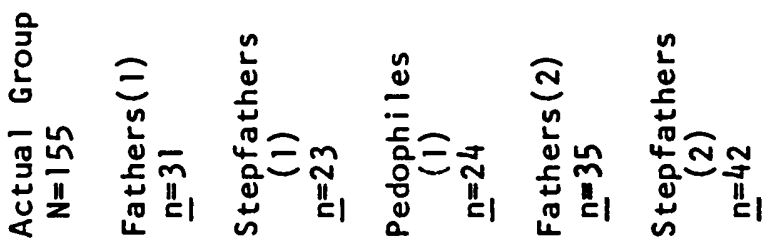

$\frac{0}{0}$

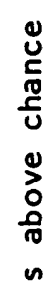

4

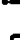

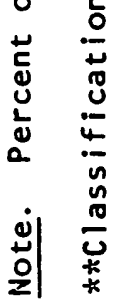


By comparing actual and predicted group memberships, using the original sample, the success of the discriminant functions and discriminant variables was empirically measured. The percent of correct classification was highest for Analys is 1 at $50 \%$, followed closely by Analyis 2 at $49.7 \%$. In both classifications, stepfathers(1) fell above chance into fathers(1), but not vice versa. Fathers(1) was above $50 \%$ predicted membership in Analysis 1 , but fell to $35.5 \%$ in Analysis 2 . In both cases fathers(1) classified into fathers(2) above chance (Rohlf \& Sokal, 1969, Table W). Of all five groups, pedophiles(1) acnieved the highest percentage of predicted membership from both analyses. Fathers(2) tended to fall into pedophiles(1) in Analysis 2. Stepfathers(2) maintained a high percentage of predicted membership in both Analyses 1 and 2 .

After the discriminant analysis program was completed, $\underline{t}$ tests were run on two variables, Age of Offender and Scale 0. As pedophiles(1) separated so distinctly, that group was not included in this analys is. Fathers(2) was compared with fathers(1) and with stepfathers(1) and (2) on both variables. The difference between fathers(2) and stepfathers(1) achieved significance $(p<.01)$ on Scale 0 only. 
CHAPTER IV

\section{DISCUSSION}

A total of five analyses were run on these data using the SPSS discriminant analysis program. On the first two analyses, the variables were limited to those containing sufficient data, thereby keeping the total $\underline{N}$ above 140 subjects. On the third and fourth analyses, variables with many missing data were run. The subsequent low sample size caused the results of the third and fourth analyses to be meaningless. A final analysis, using MMPI scale scores only, yielded discriminant variables but failed to generate statistically significant discriminant functions.

\section{COMPARISON OF ANALYSES 1 AND 2}

Analysis 1 includes the variable Alcohol Consumption Level, which separates amount of alcohol consumed into four quantitative levels. Due to its questionable accuracy, it was decided to omit Alcohol Consumption Level as a variable in Analysis 2. This removal has a marked effect, as the number of discriminant variables falls from 12 to 10 and the discriminative distance between groups decreases (see Figure 2). In particular, when the variable Alcohol Consumption Level is withdrawn from the analysis, the two variables, Sexually Abused as Child and MMPI scale 4, do not appear as discriminants. Evidently the interaction of Alcohol Consumption and these two last named variables has a discriminating effect which the two do not have by themselves.

The loss of Scale 4 as a discriminant in Analysis 2 gives a result 
which is different from past research in which Scale 4 has been an important discriminator of populations like the ones in the present study. Out of ten studies concerning either child molesters, pedophiles, or incestuous fathers, eight note that Scale 4 either has the highest elevation on the group mean profile or is significantly elevated over non-offender comparison groups (Armentrout \& Hauer, 1978; Fredrickson, 1981; Kirkland \& Bauer, 1982; Mccreary, 1975; Panton, 1978, 1979; Roby, 1982; Swenson \& Grimes, 1958). The failure of Scale 4 as a discriminant in Analysis 2 is not typical of most research on these populations. This raises the question of whether Alcohol Consumption should or should not be included in the analysis. What can one say about the accuracy of this measure?

Researchers have vigorously investigated the alcohol habits of sex offenders, presenting consumption rates ranging from 30 to $70 \%$ among offenders (Ellis, 1951; Meiselman, 1978; Rada, 1978; Swenson \& Grimes, 1958). This present study found the rate for heavy alcohol consumption to be $25.8 \%$, clearly below the levels found in other research. Rada, in particular, has noted the difficulty of evaluating the role of alcohol in sex crimes, due to the questionable accuracy of using self-report data. As Rada points out, self-report on alcoholism may be subject to the usefulness of that report to the offender (Rada, 1978, p. 48). Since the subjects in this study were either being evaluated as part of a pre-trial disposition or post-trial for possible selection into an outpatient treatment program, Rada's conclusions are persuasive. It is more likely that alcohol consumption levels have been underrated rather 
than exaggerated in this study.

In Analyses 1 and 2, pedophiles(1) and fathers(2) appear to be similar on MMPI scale 0 . This is in agreement with Langevin et al. (1978) who found Scale 0 to be elevated for all sex offenders, especially pedophiles and incest offenders. Panton (1979) found incest offenders to be significantly different from child molesters on Scale 0 , while Roby (1982) found pedophiles to score significantly higher than rapists on Scale 0 . Since the literature notes Scale 0 elevation to be characteristic of pedophiles and incest offenders, it is noteworthy that fathers(1) and stepfathers(1) and (2) are not similar to the pedophiles(1) or fathers(2). Further analysis using $\underline{t}$ tests reveals a statistically significant difference in the elevation of fathers(2) over stepfathers(1) on Scale 0 , but not between fathers(2) and the other two groups of fathers. As stepfathers(1) is farthest removed from fathers(2) in Figure 3 , this distance may be explained in part by the contribution of Scale 0 .

Without Alcohol Consumption Level in Analysis 2, Age of Offender now enters as a discriminant variable, the last to be entered in this analysis. It fails to achieve significant interaction between fathers(1), stepfathers(1), and stepfathers(2). Fathers(2) and pedophiles(1) move farther away from the above groups due to the significant interaction of Age of Offender. A $\underline{t}$ test fails to reveal a significant difference between fathers(2) and the other three incest groups on Age of Offender.

With the absence of Alcohol Consumption Level, several MMPI scales 
now contribute significantly to the interaction between fathers( 2 ) and the remaining incest groups: fathers(1) on Scales 6, 7, and 9;

stepfathers(1) on Scales K, 7, and 9; and stepfathers(2) on Scales 9 and 0 . It may be assumed that these scales, along with Age of Offender, carry information that is comparable to Alcohol Consumption Level in adding distance between the groups, but in a positive direction as shown by Function 1 in the scatterplot of Analys is 1. Stepfathers(2) moves closer to father(1) on Scale $K$ and stepfathers(1) on Highest Education Level when Age of Offender is added.

\section{NAMING THE DISCRIMINANT FUNCTIONS}

Two discriminant functions are adequate to discriminate among the five groups in both analyses. It can be seen in Figure 3 that three distinct groups appear after group centroids are plotted. It is important to remember that only the centroids are plotted and the actual scatterplot contains substantial overlap of scores from all five groups. The discriminant functions, as shown in Table VIII, are named by their dominant coefficients. Each description contains those coefficients which were weighted up to one-half the value of the largest coefficient in that function. In Analysis 1, Function 1 is labeled Marital and Alcohol Problems due to the dominance of Number of Marriages, Physical Abuse, Scale 9, Alcohol Consumption Level, Education Level, and Scale 0. Function 2 is termed Anxiety Avoidance due to the weight of Scales 7, 0 , and 1 .

When scored on the two discriminant functions, the five subject 
groups divide into three "clusters." As shown in Figure 3, pedophiles(1) form one group which is relatively socially immobile. The second group, fathers(2) appears to be heavily defended against anxiety. The third and largest group comprises a cluster of fathers(1) and stepfathers(1) and (2). This cluster is close to the total group mean. In Analysis 2, Function 1 can be termed Socially Conflicted due to the dominance of Number of Marriages and Scales 9 and 0 . Function 2 can be termed Social Avoidance due to the weight of Scales 0 and 1 and Age of Offender. Again the five groups can be regrouped as in Analysis 1. In this analysis, pedophiles(1) is characterized by social avoidance. Fathers(2) as the second group is socially introverted. The third cluster remains grouped near the total group mean. The relative distances remain constant between the three groups on both analyses. The two separate groups, pedophiles(1) and fathers(2) are further removed from the group mean than the remaining groups, with pedophiles(1) being the farthest out. It can be clearly seen that fathers(1) and stepfathers(1) and (2) are more nearly like the group means on both analyses while fathers(2) and pedophiles(1) are at extremes. The total separation of pedophiles as a distinct group is no surprise. The separation of fathers(2) is more difficult to explain, since we could also expect fathers and stepfathers to have more similarities than not.

\section{CLASSIFICATION RELIABILITY}

In discriminant analysis, classification serves two purposes. 
Initially, it tests the adequacy of the discriminant functions. Second, it can be used to identify the group membership of a suspected but nonclassified sex offender. This information should prove useful in assessment and treatment. The predicted group membership of all five groups as shown in Tables $I X$ and $X$ falls significantly above chance. Overall, the adequacy of classification is $50 \%$ in Analys is 1 and $49.7 \%$ in Analysis 2.

In Analysis 1 , the subjects fall clearly into their actual groups with the exception of stepfathers(1) who are classified at a significant percentage into fathers(1). It is interesting to note that fathers(1) is misclassified more often as fathers(2) than as stepfathers(1). This is clearly an indication that stepfathers(1) more nearly mimics fathers(1) than vice versa. If indeed both stepfather groups report their life experiences in a similar way as to be classified as fathers(1), then fathers with a blood relationship to the victim may not differ from stepfathers who have a proximity relationship. This evidence may refute Meiselman's (1978) contention that girls having stepfathers are at a greater risk than girls having fathers. However, until the separation of fathers(2) from the other three incest groups can be understood, the kinship versus blood relation theory must remain a viable alternative. One possibility may be that if the victim of the stepfather has been in proximity to him for sufficient time to create a deep bond, the relationship is more similar to father-daughter. If this is true, then bonding is the true factor rather than blood or kinship relations. 
In Analysis 2, the groups again are accurately classified into their actual groups in a significant way. Stepfathers(1) again falls into fathers(1) at a slight increase in percentage which suggests that the two groups differ to a small degree on alcohol consumption in Analysis 1. It is noteworthy that after Alcohol Consumption is removed, the percentage of fathers(2) classified as pedophiles(1) increases significantly. In light of pedophiles' separation on Figure 2 , this is surprising information. Clearly, Alcohol Consumption Level is a major factor separating the two groups. This information confirms Groth's (1979) opinion that alcohol is used more by the incest offender than by the pedophile, due to the child-like psychological makeup of the latter. It remains to be discussed whether a classification rate of $50 \%$ is accurate for assessment and treatment purposes. If we were classifying two groups, the answer would immediately be no. Since the five groups separated into three groups (see figure 3 ), we may speculate that classification into three groups would have a chance rate of $33.34 \%$. In Analysis 2, given that fathers(1) and stepfathers(1) and (2) appear to be one group, erroneous grouping still occurs as fathers(1) falls into fathers(2) and fathers(2) falls into pedophiles(1). In Analys is 1, there would be no erroneous grouping if fathers(1) and stepfathers(1) and (2) were considered a single group. The individual group percentages for the true group fall above chance and are significant, thereby making the classification rate statistically acceptable. However, in an actual treatment or assessment situation, this same rate would not be acceptable, but would have to be increased. 


\section{CONCLUSIONS AND RECOMMENDATIONS}

The variables used in studying the sex offender groups do not discriminate sufficiently. A study of the MMPI scale scores by groups in Table IV and the lack of a significant function from Analysis 5 shows that the MMPI scales alone cannot separate sex offenders. This evidence is supported by the reported failure of Marsh et al. (1955) to distinguish between pedophiles and incest offenders using the MMPI. Table II shows that pedophiles and incest offenders have only been separated significantly by Pittman (1982) on Scale 2, a finding not replicated by this study.

Demographic variables have only begun to be studied in depth. As yet, definitions for such quantitative variables as Alcohol Consumption Level remain to be clearly stated and agreed upon by the community. Accurate assessment of the amount of alcohol consumed must take into account the height, weight, and tolerance of the individual. Selfreport on physical and sexual abuse experiences as a child is subject to the memory of the individual as well as the meaning of that information to the offender. As has been mentioned earlier, information carrying legal consequences, such as incarceration, are very likely to be minimized or inaccurate. Analyses 3 and 4 could not be completed because missing data lowered the $\underline{N}$ to an unacceptable lever. Unfortunately, these analyses included several measures which may warrant more attention. Specifically four variables would be well worth further research and rigorous coding: adopted, foster care, number of incarcerations, and number of arrests. With Rada's (1978) warning in 
mind, it might be feasible to verify self reports on arrests through legal records and reports on abuse through family members.

The coding of the data, especially demographic variables, most certainly introduced error into the study. Two different students were responsible for coding the samples: one student coded group 1 from the clinical psychologist and trained the second student, who then coded group 2. As much material on the individual offenders is in the form of summary accounts of clinical interviews, extraction of some data had to be made subjectively. As has been mentioned earlier, alcohol consumption levels were difficult to code, especially moderate drinking. This author, who was the second coder, took a conservative stance, electing to code as "missing data" unless the answer was reasonably clear.

The differences between the two sample groups of fathers and stepfathers may be traced to the selection and assessment practices of the two sources of data, the clinical psychologist and Providence Day Treatment Program (see p. 14). The clinical psychologist evaluates sex offenders primarily in pre-trial assessments for placement into therapy programs, psychological screening for legal purposes, and to determine potential for therapy. Accused sex offenders are sent to him by lawyers and court referrals from the Oregon and Vancouver, Washington area. No selectivity is practiced in screening clients, as this interview is for evaluation and dispositional purposes only. It is possible that this larger group differs from the smaller population from Providence on socio-economic levels or in other ways which have not as yet been 
investigated.

The program at Providence exercises a selective screening procedure in that brain-damaged individuals, drug abusers, men who lack a sense of remorse, who are violent, or who have been diagnosed as psychotic are el iminated from the program. As the purpose of the program is to deliver successful treatment, potential failures are weeded out. Primarily, the clients are referred by Children's Services Division (CSD) or mandated by the courts and come under duress, as the alternative is incarceration. Assessment at Providence is done by a team of evaluators after the offender has gone through the legal system and has been found guilty of sexual abuse. It is possible that in being screened for selection into the program at Providence, the very subjects who fall near the boundary between fathers and stepfathers are eliminated, thus allowing the two groups from Providence to appear distinct.

Besides the different assessment goals of the two clinics, the pretrial condition of the majority of group 1 and the post-trial condition of group 2 may contain some factor that influences group separation on one hand and blurring on the other. Whichever the case, such a factor has not as yet been isolated and is made murky since fathers(2) separates clearly from the three incest groups while stepfathers(2) clusters with both stepfathers(1) and fathers(1).

In conclusion, use of the SPSS discriminant analys is program allowed descriptive profiles to be drawn on sex offenders by a comparison of the information provided by 30 variables across 177 
subjects. The program tested the information provided by the variables through group pair-wise interaction in five separate analyses, of which two proved useful. From these analyses four significant discriminant functions were drawn with which the subjects were re-classified to test statistically-predicted versus actual group membership. The approximately $50 \%$ accuracy in classification is considered acceptable as five groups were being run. At the same time this rate of prediction is inadequate as a basis for major assessment and treatment recommendations until clearer group distinctions can be made.

Finally, it is recommended that clarification of variable definitions be pursued in future studies along with a check on the accuracy of self-report information that could be verified through legal records and confirmation by family members. Error could be reduced by including two independent coders to establish reliability. Subtle differences may be found to exist in the pre-trial evaluation done by the private clinical psychologist and the post-trial screening necessary at the Day Treatment Program. While the statistical profiles obtained from this study are not reliable enough for treatment and assessment decisions by themseives, with further refinement they could become usefur. 


\section{A SELECTED BIBLIOGRAPHY}

Anderson, W. P., Kunce, J. T., \& Rich, B. (1979). Sex offenders:

Three personality types. Journal of Clinical Psychology, $35(3)$, 671-676.

Armentrout, J. A., \& Hauer, A. L. (1978). MMPI's of rapists of adults, rapists of children, and non-rapist sex offenders. Journal of Clinical Psychology, 34(2), 330-332.

Bernard, F. (1975). An enquiry among a group of pedophiles. Journal of Sex Research, 11(3), 242-255.

De Francis, V. D. (1969). Protecting the child victim of sex crimes committed by adults (pp. 66-70, 89-90). Denver: The American Humane Association.

Ellis, A. (1961). A study of 300 sex offenders. International Journal of Sexology, $4,127-135$.

Finkelhor, D. (1979). Sexually victimized children. New York: The Free Press.

Fredrickson, R. M. (1981). Incest: Family sexual abuse and its relationship to pathology, sex role orientation, attitudes toward women, and authoritarianism (Doctoral dissertation, University of Minnesota, 1981). Dissertation Abstracts International, 42(01-B), 372.

Freud, S. (1896). Heredity and the aetiology of the neurosis. Further remarks on the neuro-psychoses of defence. The aetiology of hysteria. In J. Strachey (Ed.) (1962). The standard edition of the complete psychological works of Sigmund Freud, Vol. III. London: The Hogarth Press.

Groth, A. N. (1979). Men who rape. New York: Plenum Press.

Henn, F. A., Herjanic, M., \& Vanderpearl, R. H. (1976). Forensic psychiatry: Profiles of two types of offenders. American Journal of Psychiatry, 133(6), 694-696.

Holz, W. C., Harding, G. F., \& Glassman, S. M. (1957). A note on the clinical validity of the Marsh-Hilliard-Liechti scale. Journal of Consulting Psychology, 21, 376. 
Kaplan, R. M., \& Saccuzzo, D. P. (1982). Psychological testing: Principles, applications, and issues (p. 371). Belmont, CA: wadsworth, Inc.

Karpman, B. (1957). The sexual offender and his offenses (pp. 5-20). Washington, DC: Julian Press, Inc.

Kirkland, K. D., \& Bauer, C. A. (1982). MMPI traits of incestuous fathers. Journal of Clinical Psychology, 38(3), 645-649.

Kleck, W. R. (1970). Discriminant analysis. In N. H. Nie, C. H. Hull, J. G. Jenkins, K. Steinbrenner, D. H. Bent (Eds.), Statistical package for the social sciences (2nd ed.) (pp. 434-462). New York: McGraw HiTT Book Co.

Lachar, D. (1974). The MMPI: Clinical assessment and automated interpretation (pp. 19-21). Los Angeles: Western Psychotogical services.

Langevin, R., Paitich, D., Freeman, R., Mann, K., \& Handy, L. (1978). Personality characteristics and sexual anomalies in males. Canadian Journal of Behavioral Sciences, 10(3), 222-238.

Marsh, J. T., Hilliard, J., \& Liechti, R. (1955). A sexual deviation scale for the MMPI. Journal of Consulting Psychology, 19, 55-59.

Meiselman, K. C. (1978). Incest. San Francisco: Jossey-Bass.

McCreary, C. P. (1975). Personality differences among child molesters. Journal of Personality Assessment, 39(6), 591-593.

Panton, J. H. (1978). Personality differences appearing between rapists of adults, rapists of children, and non-violent sexual molesters of female children. Research Communications in Psychology, Psychiatry, and Behavior, $3(4), 385-393$.

Panton, J. H. (1979). MMPI profile configurations associated with incestuous and non-incestuous child molesting. Psychological Reports, 45(1), 335-338.

Peek, R. M., \& Storms, L. H. (1956). Validity of the MarshHilliard-Liechti MMPI sexual deviation scale in a state hospital population. Journal of Consulting Psychology, 20, 133-136.

Pelto, V. L. (1981). Male incest offenders and nonoffenders: A comparison of early sexual history (Doctoral dissertation, United States International University, 1981). Dissertation Abstracts International, 42(03-B), 1154. 
Pittman, S. G. (1982). A personality profile of pedophiliac and incestuous child molesters: A comparative study. Dissertation Abstracts International, 42(12-B), 4939. (University Microfilms, No. 82-11074).

Rada, R. T. (1978). Clinical aspects of the rapist (pp. 48-50). New York: Grune \& Stratton.

Renvoize, J. (1982). Incest: A family pattern. London: Roultedge \& Kegan Paul, Ltd.

Roby, C. Y. (1982). I. A Comparison of rapists with nonaggressive pedophiles and nonoffenders on the MMPI and two hostility scales. II. Rapists' perceptions of victim, self, and significant others. (Doctoral dissertation, Brigham Young University, 1982). Dissertation Abstracts International, 43(03), 883.

Rohlf, F. J., \& Sokal, R. R. (1969). Statistical tables. Table W. Confidence limits for percentages. San Francisco: W. H. Freeman.

Sgroi, S. M. (1982). Handbook of clinical intervention in child sexual abuse (pp. 9-39). Lexington, MA: Lexington Books.

Skinner, H. A., \& Jackson, D. N. (1978). A model of psychopathology based on an integration of MMPI actuarial systems. Journal of Consulting and Clinical Psychology, 46, 231-238.

Swanson, D. W. (1968). Adult sexual abuse of children. Diseases of the Nervous System, 29, 677-683.

Swenson, W. M., \& Grimes, B. P. (1958). Characteristics of sex offenders admitted to a Minnesota state hospital for pre-sentencing psychiatric investigation. Psychiatric Quarterly Supplement, 31 , 110-123.

Toobert, S. K., Bartelme, K. F., \& Jones, E. S. (1959). Some factors related to pedophilia. International Journal of Social Psychiatry, 4, 272-279.

Yamahiro, R. S., \& Griffith, R. M. (1960). Validity of two indices of sexual deviancy. Journal of Clinical Psychology, 16, 21-24. 
APPENDIX A

DEMOGRAPHIC QUESTIONNAIRE \& RAW DATA FREQUENCIES 
DEMOGRAPHIC QUESTIONNAIRE

Age: age of offender at time of evaluation at both clinics.

Education level: the highest of four levels of school the offender obtained: 1st-8th, 9th, 10th, 11th, 12th, GED, 13th, 14th, 14th+.

Age at first marriage:

Number of marriages:

Number of arrests as a juvenile: any arrests the offender experienced before age 18 .

Number of arrests as an adult: all arrests the offender experienced after 18, excluding the present arrest.

Number of jobs held since 16 years old:

Military service: yes/no.

Number of past psychiatric inpatient treatments: number of times the offender has been hospitalized for psychological reasons, excluding the present offense.

Number of past periods of outpatient treatment: number of outpatient treatment periods, excluding the present offense.

Number of past incarcerations: excluding the present offense.

Alcohol consumption level: offender's drinking habits as coded into one of four levels of consumption.

none

social: occasional beer or hard liquor

moderate: a couple of beers a night, a drink or glass of wine. heavy: alcohol dependence or heavy consumption.

Recreational drug usage (other than prescription drugs): yes/no.

Adopted: yes/no.

Foster care: yes/no.

Physically abused as child: yes/no.

Sexually abused as child: yes/no. 


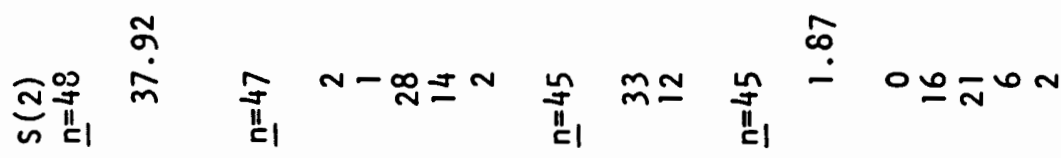

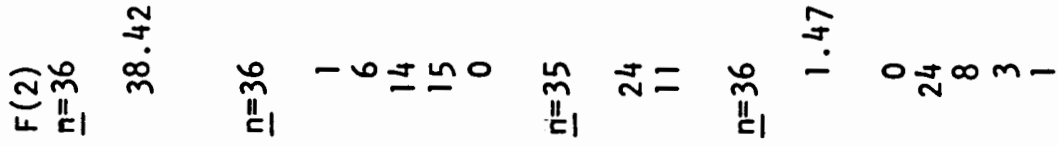

唁

ํㅗㅇ

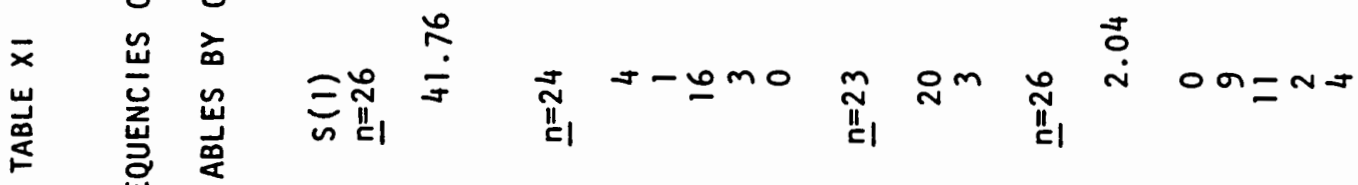

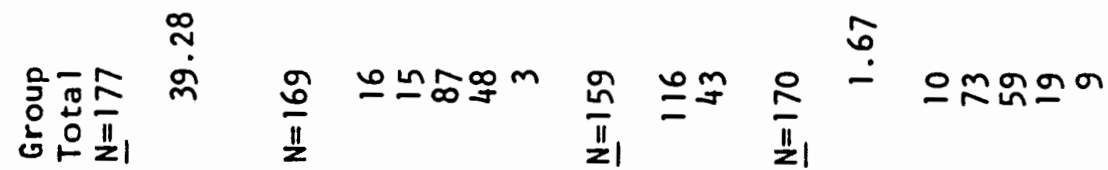

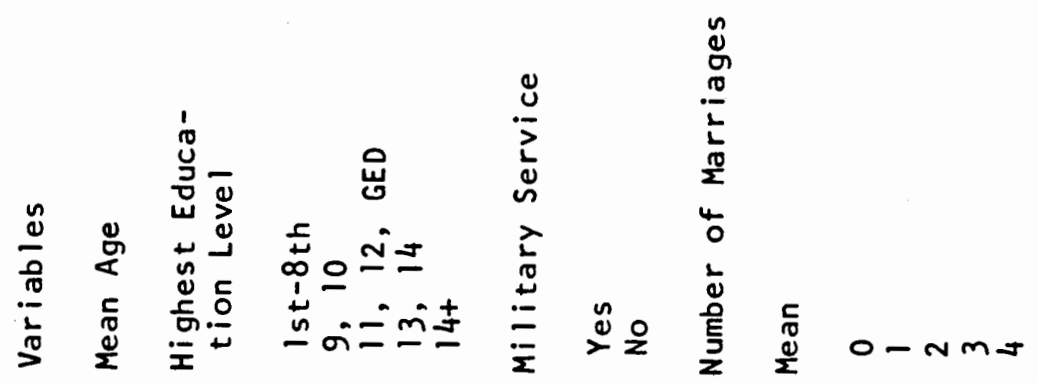




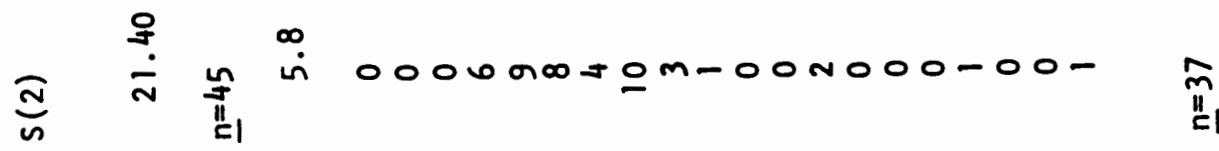

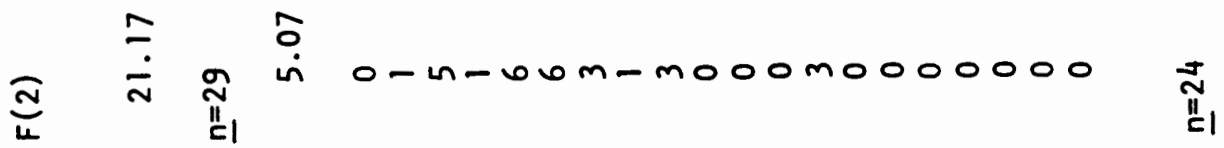

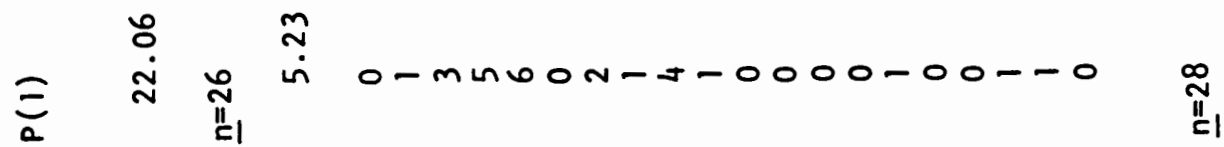

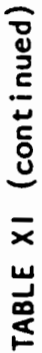

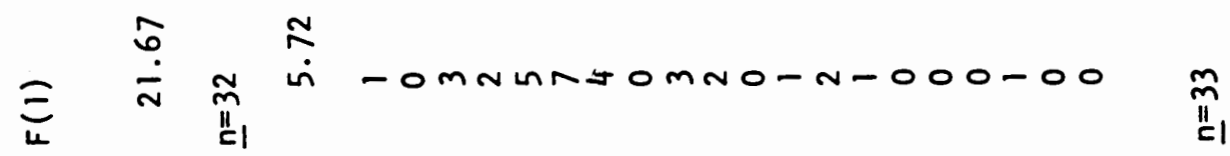

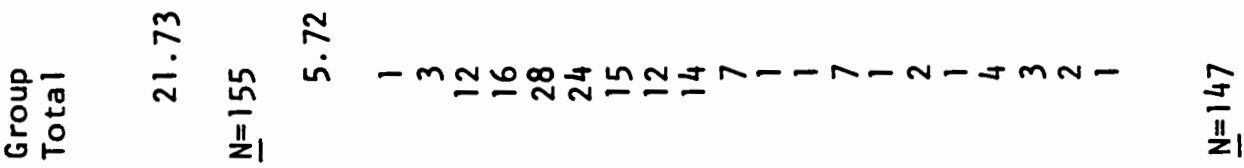

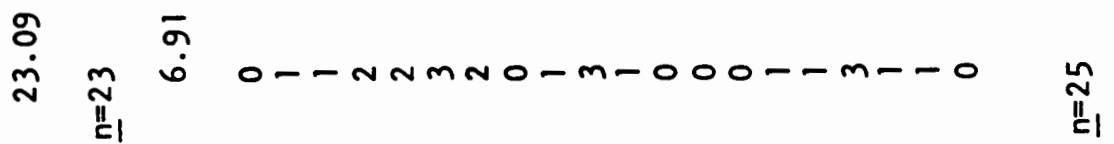

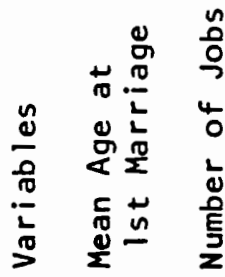

尊 


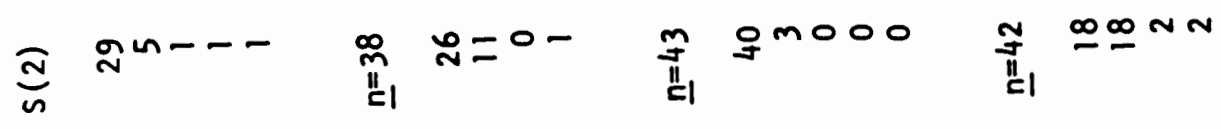

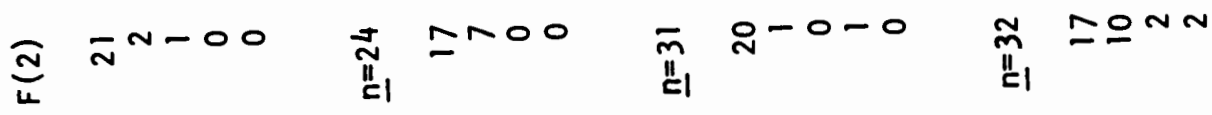

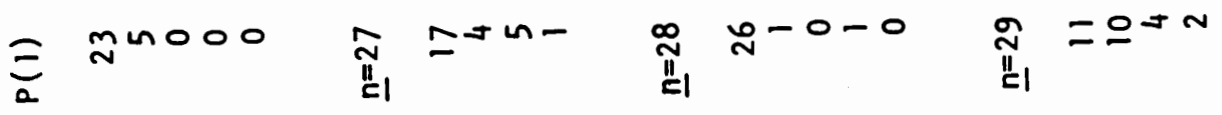

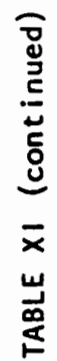

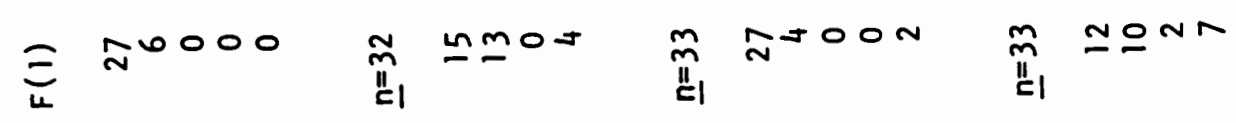

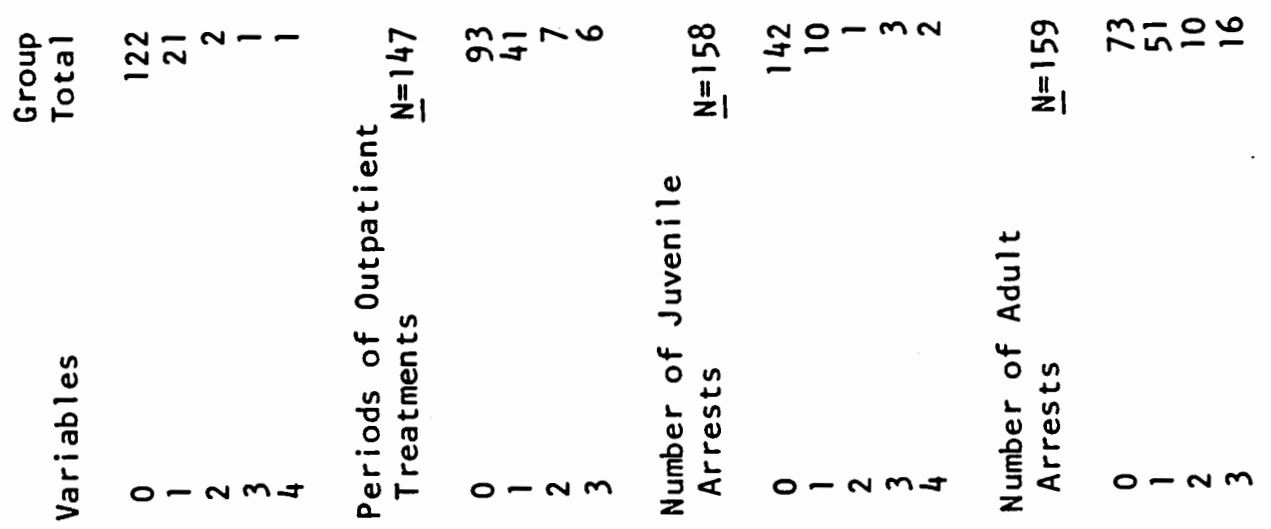




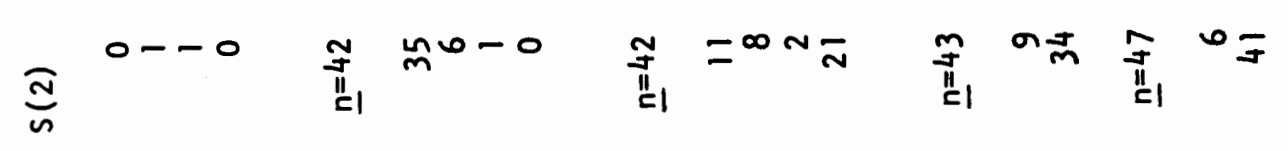

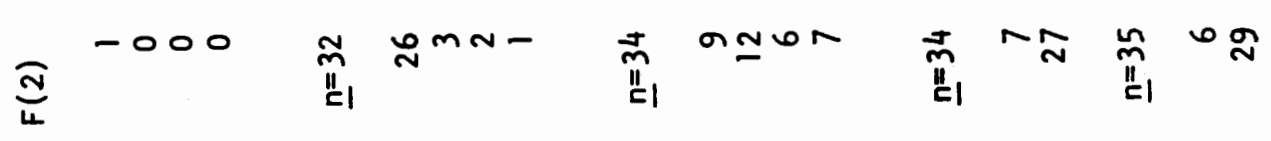

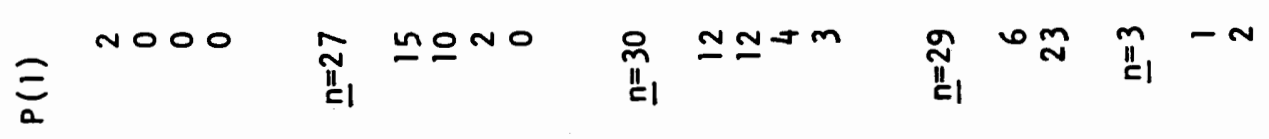

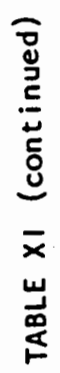

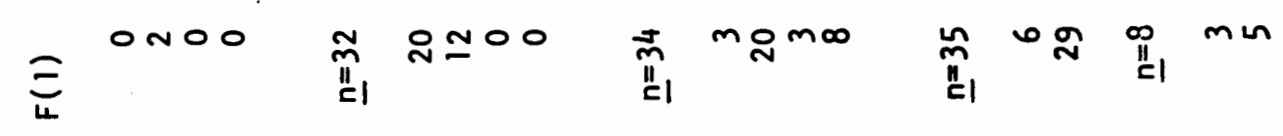

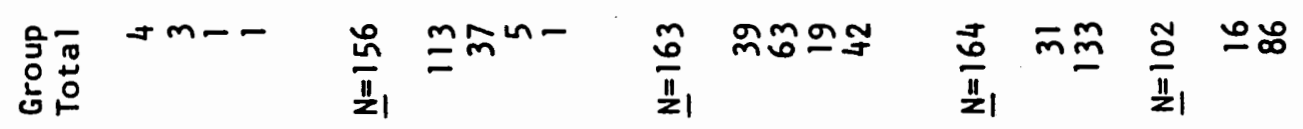

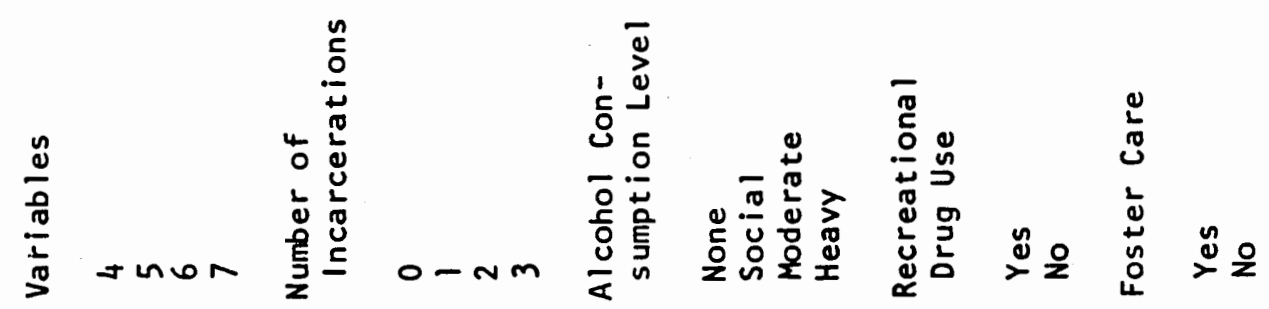




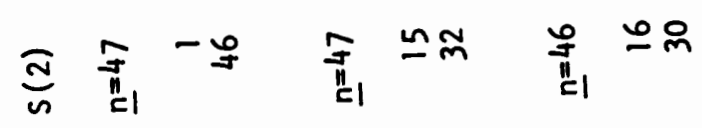

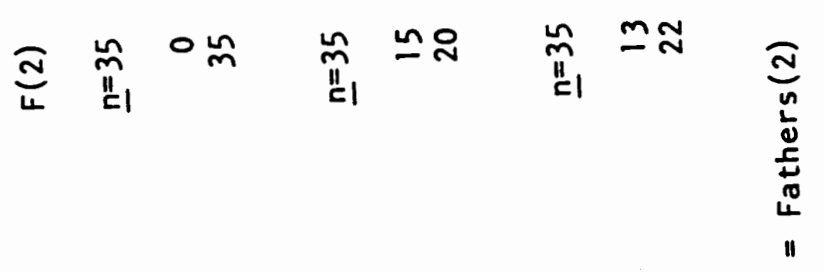

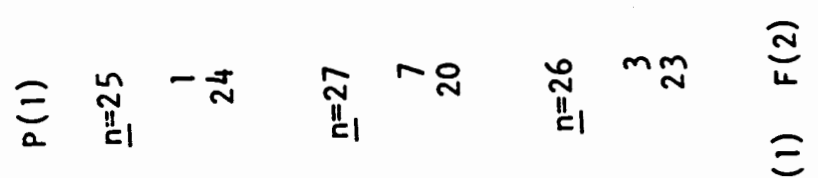

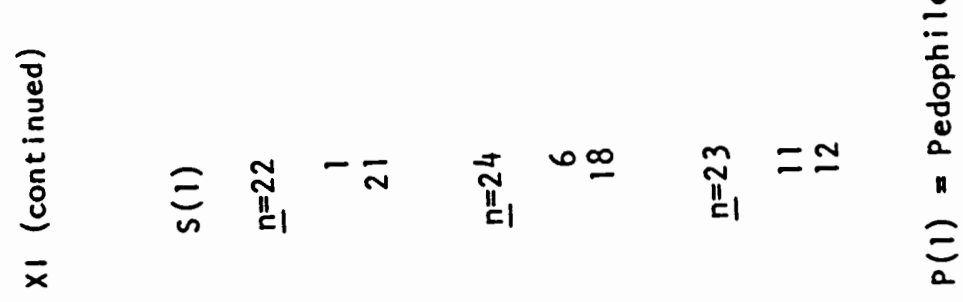

$$
\begin{aligned}
& \text { 峞 }
\end{aligned}
$$

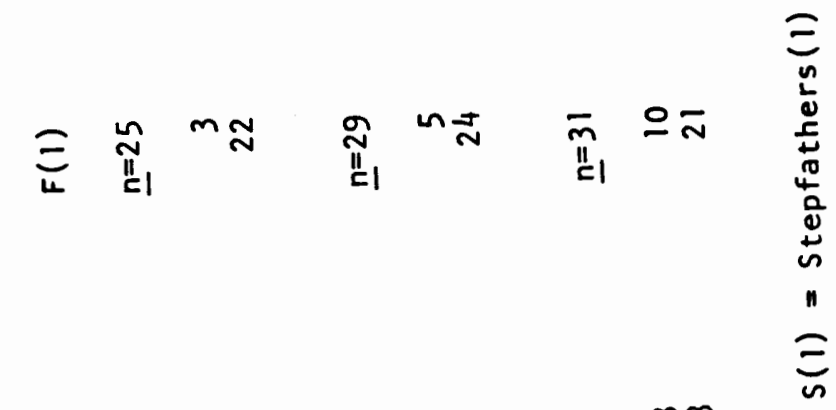

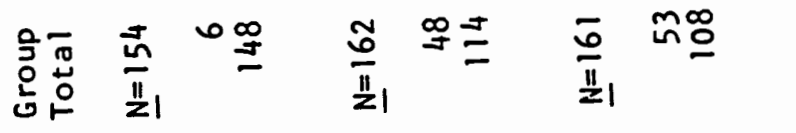

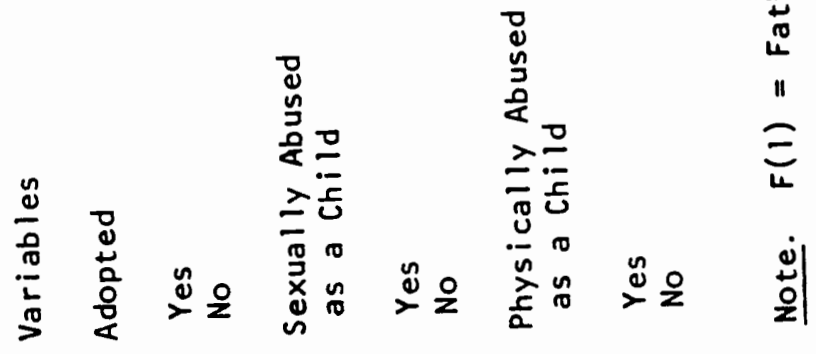


APPENDIX B

ANALYSES 1 AND 2 SIGNIFICANCE LEVELS 
$\equiv$

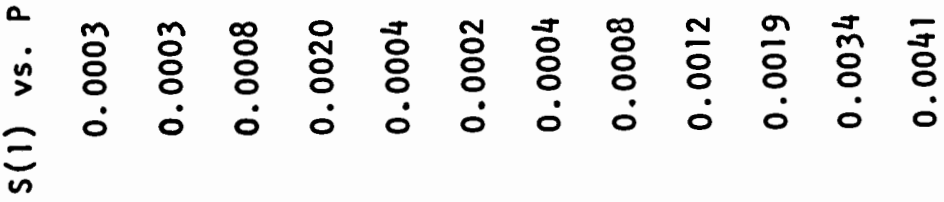

$\bar{\Sigma}$

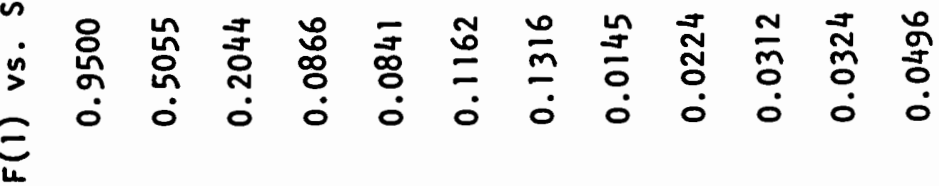

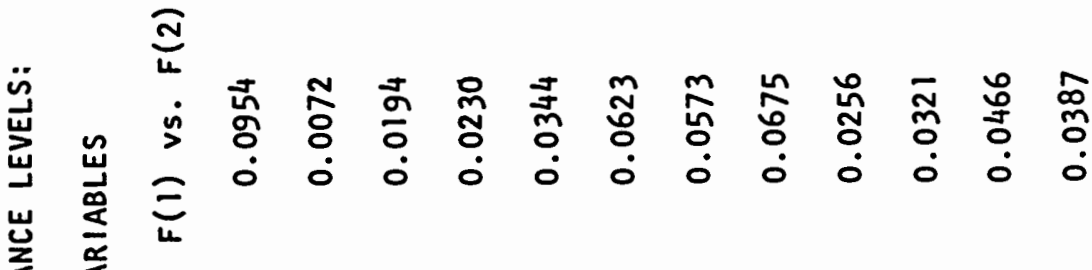

$\overline{\bar{x}} \quad$ 悹

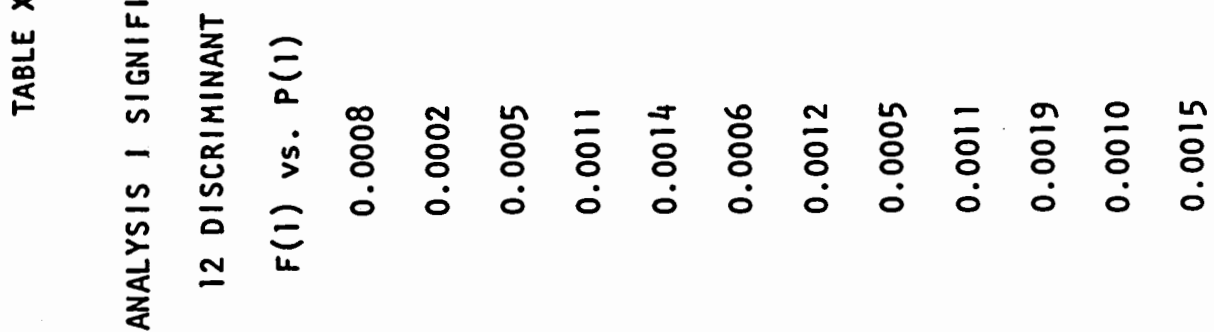

$\Xi$

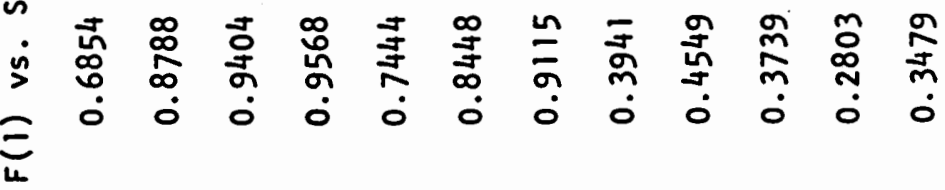

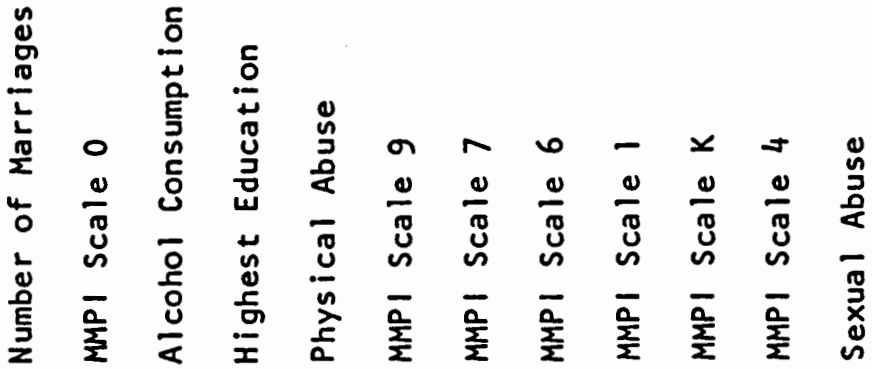


ลิ

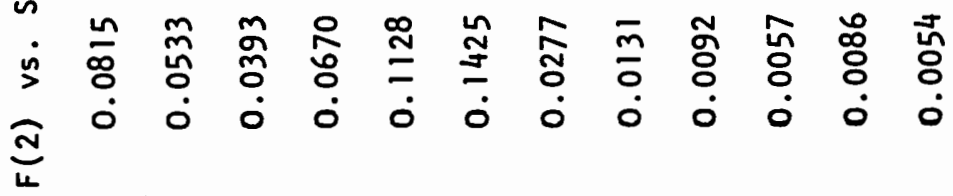

ลัง

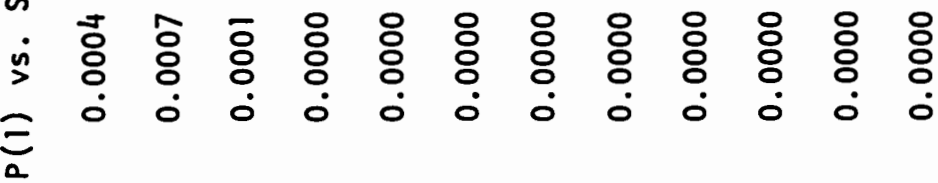

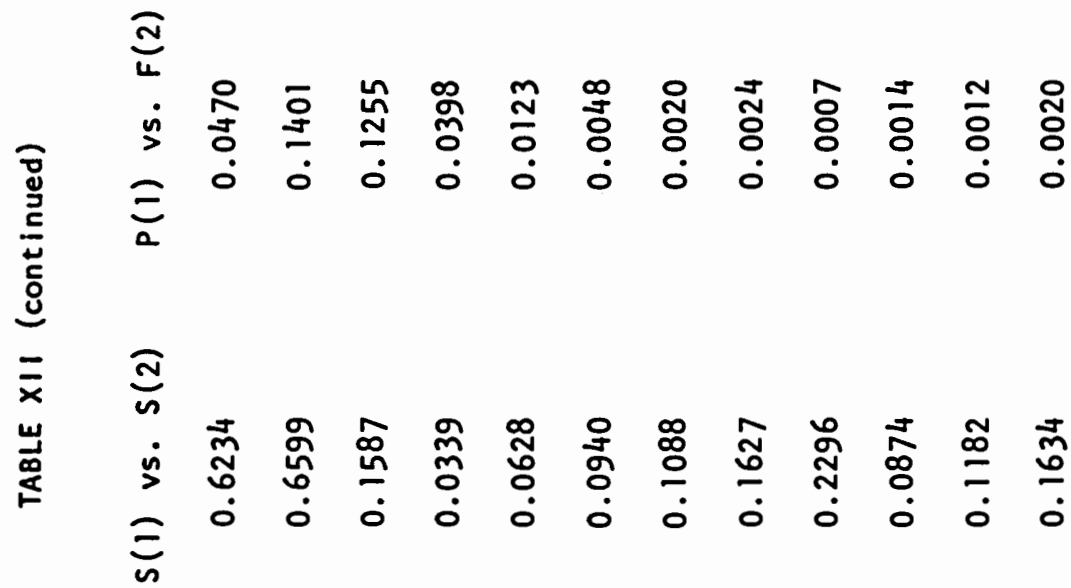

근

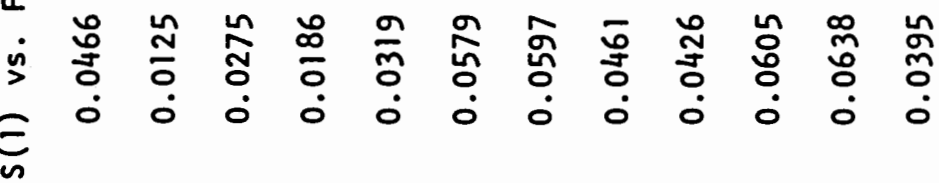

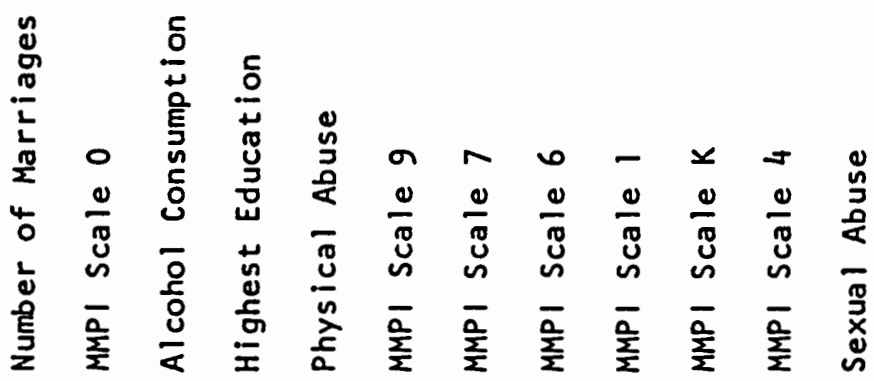


$\equiv$

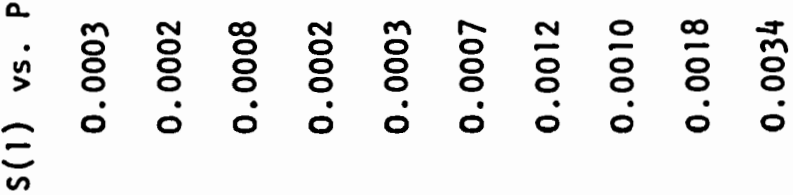

$\frac{\pi}{n}$

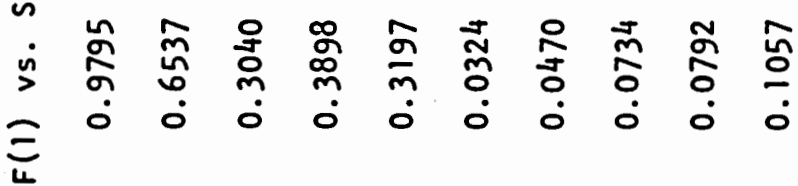

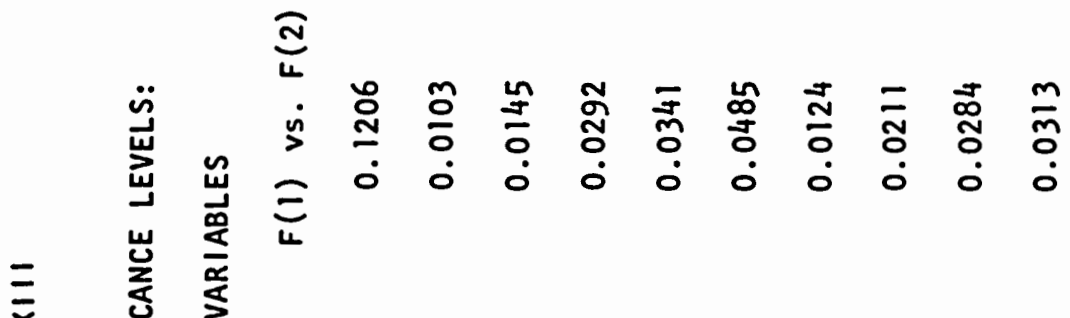

效 岕

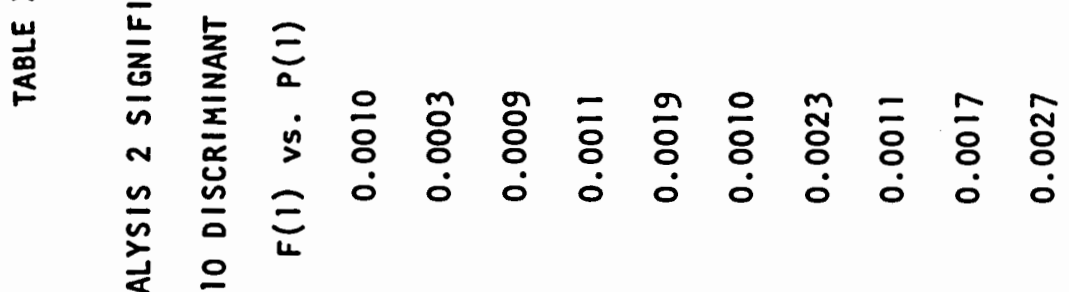

$\sum_{\text {is }}$

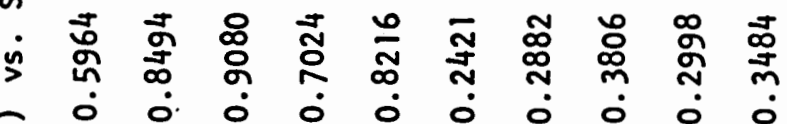

三

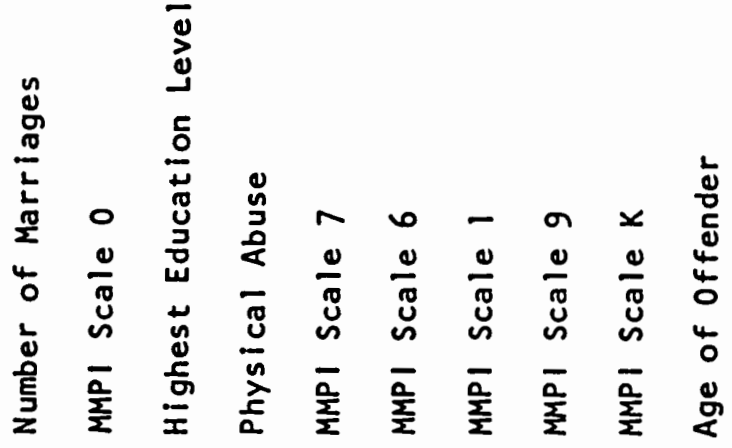


กับ

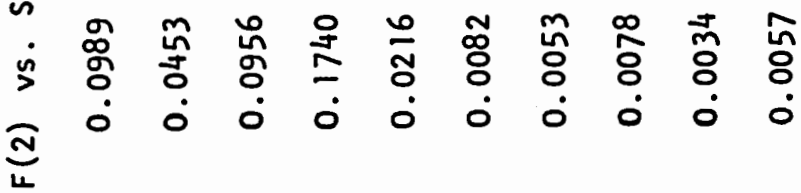

$\frac{\pi}{n}$

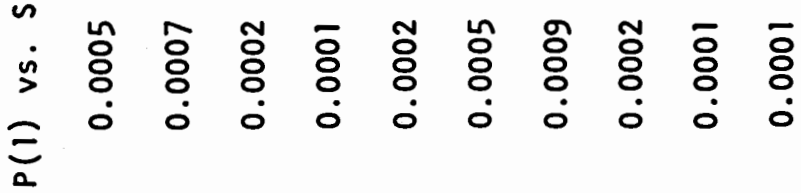

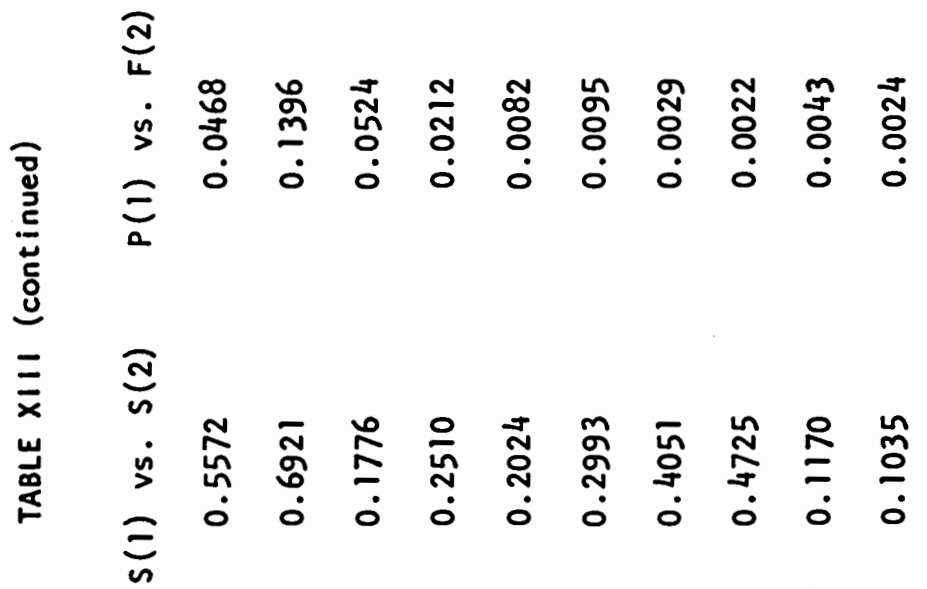

ลัธ

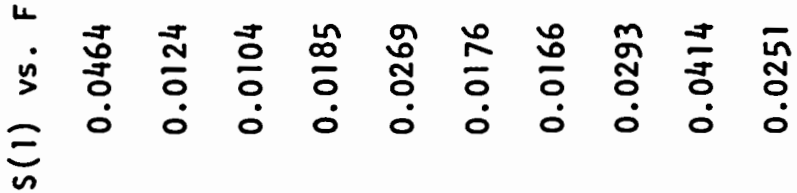

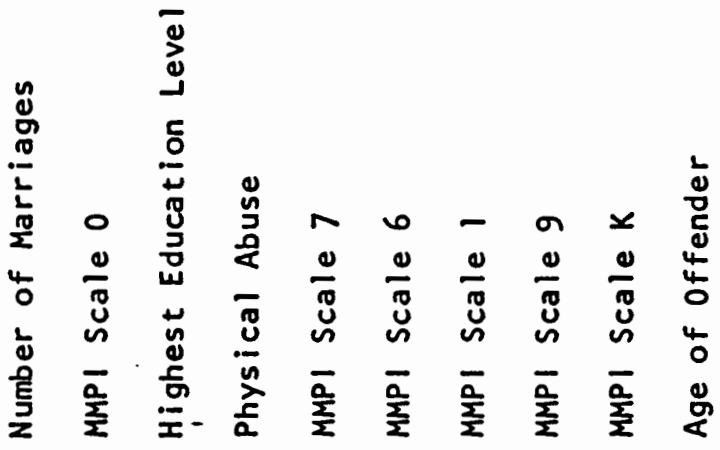

